\title{
Los mayas del altiplano: supervivencia indígena en Chiapas y Guatemala ${ }^{1}$
}

W. George Lovell

Queen's University, Canadá

En el contexto americano, pocos grupos indígenas han demostrado la capacidad de sobrevivir a lo largo de la historia como los mayas del altiplano. Hoy día en Chiapas existen más de un millón de indígenas mayas, un número que asciende a cinco o seis millones en el caso de Guatemala. Los pueblos mayas han respondido a la invasión y a la dominación para conservar elementos importantes de su cultura. Este artículo discute las formas en que los mayas del altiplano se han adaptado para sobrevivir a casi cinco siglos de conquista, identificando tres fases claves en su trayectoria histórica: (1) la experiencia colonial, que abarca los años entre 1524 y 1821; (2) una época de reforma y revolución, que corre de 1821 a 1954; y (3) un período de marginalización y descuido desde 1954 en adelante. Pese al desfío, los mayas del altiplano están equipados culturalmente para perdurar.

Poco a poco grandes sombras y completa noche envolvieron a nuestros padres y abuelos y a nosotros también, ¡oh hijos míos!....Todos quedamos así. ¡Para morir nacimos!

Memorial de Sololá

A pesar del lamento del cronista kaqchikel, escrito a mediados del siglo XVI, los mayas del altiplano mantienen una presencia vibrante que ningún americanista puede descartar. Incluso los censos gubernamentales moder-

1 Este artículo refleja un interés personal en el tema que se remonta a mi primera visita a Chiapas y Guatemala, viaje que occurió en 1974. Desde entonces, no sólo he tenido la oportunidad de explorar el altiplano maya, sino de realizar investigaciones históricas sobre él y sus habitantes en otras partes, especialmente en el Archivo General de Indias en Sevilla. A través de los años, mi trabajo ha sido financiado por la University of Alberta, la Queen's Universty, el Killam Program of the Canada Council, el Social Sciences and Humanities Research Council of Canada y el Ministerio de Educación y Cultura de España. Otra versión del artículo, en inglés, fue publicado en Richard E.W. Adams y Murdo J. MacLeod, editores, The Cambridge History of the Native Peoples of the Americas, Vol II, Part 2, Mesoamerica (New York: Cambridge University Press, 2000), págs. 392-444. Para esta versión en castellano se han hecho varias modificaciones y revisiones al texto original. El argumento central - supervivencia cultural no obstante la dura realidad de un proceso de conquista que todavía sigue - también se ha articulado en lecturas, mesas redondas, y ponencias presentadas en la Escuela de Estudios Hispano-Americanos, la Universidad Internacional de Andalucía, la Universidad de Sevilla y la Universidad Pablo de Olavide. A mis colegas en estas instituciones, y a sus energéticas cantidades de estudiantes, quiero expresar mi aprecio y gratitud. Como en otras ocasiones, la mano creativa del Dr. Eddy Gaytán, lingüista y traductor, me ayudó mucho. 
nos, que tienden a enumerar menos indígenas de los que en realidad hay, registran poblaciones mayas considerables, actualmente más de un millón en el estado mexicano de Chiapas y entre cinco y seis millones en el caso de Guatemala. Si, en el contexto nacional de México, los mayas de Chiapas existen como una de docenas de minorías indígenas entre una masa de mestizos, sus contrapartes del otro lado de la frontera constituyen una fuerza demográfica más palpable, ya que los pueblos mayas comprenden aproximadamente la mitad de la población de Guatemala (Cuadros 1-4). Los números son importantes pero, aislados, meramente rasguñan la superficie de nuestra exposición. Sólo contemplando a los mayas desde una perspectiva histórica puede ser apreciada, más completamente, su conspicua presencia.

¿Quiénes son estos pueblos nativos? ¿Cómo, a través de los siglos, se las han arreglado para sobrevivir? ¿Qué clases de vidas han vivido? ¿Por qué debería preocuparnos su suerte? Tales preguntas han encendido debates durante bastante tiempo, desde la valiente postura adoptada por europeos ilustrados como Bartolomé de las Casas, fraile dominico que defendió los derechos de los indígenas en el siglo XVI, hasta la voz apasionada de Rigoberta Menchú, mujer maya cuya condecoración con el Premio Nobel de la Paz en 1992, al igual que los comunicados del subcomandante Marcos después de la sublevación zapatista en 1994, centraron la atención internacional en iniquidades más recientes, amenazas más recientes a la supervivencia maya.

\section{CUADRO 1}

LOS MAYAS DEL ALTIPLANO DE CHIAPAS, 1950-90

Año Población maya Porcentaje de población mexicana total

\begin{tabular}{llr}
\hline 1950 & 160.000 & 0,62 \\
1980 & 390.000 & - \\
1990 & 617.250 & 0,61
\end{tabular}

Fuente: Para 1950, véase Flores, Anselmo Marino: "Indian Population and Its Identification,” en Handbook of Middle American Indians, vol. 6, Austin: University of Texas Press, 1967, pág. 20, y Vogt, Evon Z.: "The Maya," en Handbook of Middle American Indians, vol. 7, Austin: University of Texas Press, 1969, pág. 23; para 1980, véase Ligorred, Francesc: Lenguas indígenas de México y Centroamérica, Madrid: Editorial MAPFRE, 1992, pág. 223; y para 1990, véase La Jornada, 15 de diciembre de 1991. Rus, Jan: "Local Adaptation to Global Change: The Reordering of Native Society in Highland Chiapas, Mexico, 1974-1994," en European Review of Latin American and Caribbean Studies 58, Amsterdam, 1995, pág. 75, proporciona una cifra de 847.751 para la población indígena de Chiapas en 1990. Esta cifra incluiría un número de indígenas no mayas. 
CUAdro 2

LOS MAYAS DEL ALTIPLANO DE GUATEMALA, 1950-94

\begin{tabular}{ccc} 
Año & $\begin{array}{c}\text { Cómputo censal nacional } \\
\text { de población maya }\end{array}$ & $\begin{array}{c}\text { Porcentaje de población } \\
\text { guatemalteca total }\end{array}$ \\
\hline 1950 & 1.495 .905 & 53,6 \\
1964 & 1.809 .535 & 42,2 \\
1973 & 2.260 .024 & 43,8 \\
1980 & 2.536 .523 & 41,9 \\
1994 & 4.037 .449 & 42,8
\end{tabular}

Fuente: W. George Lovell y Christopher H. Lutz, "A Dark Obverse': Maya Survival in Guatemala, 1520-1994,” en Geographical Review 86, 3 (1996): pág. 400.

\section{Cuadro 3}

HABLANTES DE IDIOMAS MAYAS EN CHIAPAS, 1950-90

\begin{tabular}{|c|c|c|c|}
\hline \multirow[b]{2}{*}{ Grupo lingüístico } & \multicolumn{3}{|c|}{ Número de hablantes } \\
\hline & $(1950)$ & $(1980)$ & (1990) \\
\hline Tzeltal & 75.000 & 200.000 & 306.000 \\
\hline Tzotzil & 48.250 & 150.000 & 268.500 \\
\hline Tojolabal & 37.000 & 40.000 & 42.500 \\
\hline
\end{tabular}

Fuente: Para 1950, véase Flores, Anselmo Marino: "Indian Population and Its Identification," en Handbook of Middle American Indians, vol. 6, Austin: University of Texas Press, 1967, pág. 22 y Evon Z. Vogt, "The Maya," en Handbook of Middle American Indians, vol. 7, Austin: University of Texas Press, 1969, pág. 23; para 1980, véase Francesc Ligorred, Lenguas indígenas de México y Centroamérica, Madrid: Editorial MAPFRE, 1992, pág. 223; y para 1990, véase La Jornada, 15 de diciembre de 1991. De Vos, Jan: Vivir en frontera: La experiencia de los indios de Chiapas, Ciudad de México: Instituto Nacional Indigenísta, 1994, pág. 35, proporciona una cifra de 716.012 personas en Chiapas que pueden hablar "alguna lengua autóctona." Esta cifra incluiría un número de hablantes nativos no mayas. Véase también Viqueira, Juan Pedro: "Chiapas y sus regiones," en Viqueira, Juan Pedro, y Ruz, Mario Humberto (editores): Chiapas: Los rumbos de otra historia (México: Universidad Nacional Autónoma de México, 1998), págs. 19-40.

La supervivencia misma es la cuestión clave, pero se trata de una cuestión que debemos considerar cuidadosamente. Debemos proceder con cautela, para no romantizar o simplificar lo que pasó en la historia. Las páginas de National Geographic están llenas de retratos lustrosos de pue- 
blos mayas que aparecen como reliquias anacrónicas, recuerdos de una edad dorada anterior a la conquista española. Los textos marxistas cultivan otra imagen, una imagen en la que los pueblos mayas aparecen como víctimas inertes, forjadas y preservadas por la explotación colonial y neocolonial. Ninguna de las dos construcciones corresponde a lo que ahora sabemos que han sido experiencias variables, ya que la confrontación entre los indígenas y los no indígenas fue algo que se diferenció bastante marcadamente de región a región, si no de un lugar a otro dentro de una región. Si consideramos a los mayas como sujetos, no como objetos, si vemos más allá de mitos anticuados y estereotipos clichés, entonces tal vez podemos verlos como actores sociales, como agentes humanos que responden a la invasión y la dominación para moldear, por lo menos en parte, elementos importantes de su cultura.

Este artículo delinea algunas de las formas en que los mayas del altiplano han reaccionado y respondido para sobrevivir a casi cinco siglos de conquista. Para construir una narrativa, se coloca la evidencia en forma de pirámide, pirámide en la que la base del tiempo pasado se va estrechando hacia la cúspide del tiempo presente. Tal estructura está diseñada para poner de relieve las fuerzas históricas que dan forma a, y el contexto histórico que enmarca, las penalidades actuales. La experiencia colonial, que abarca los años entre 1524 y 1821, recibe especial atención, ya que fue durante este período cuando se moldeó irreductiblemente la desigualdad que imperó en épocas posteriores. Las vicisitudes de la vida maya en los siglos XIX y XX se tratan más sumariamente en dos períodos, uno de reforma y revolución de 1821 a 1954, otro de marginalización y descuido desde 1954 en adelante. En la descripción de patrones amplios y tendencias generales se incluyen casos específicos, mecanismo que nos permite obtener un equilibrio entre proporcionar datos esenciales y dar detalles.

\section{La experiencia colonial}

Después de sus logros en Tenochtitlán, cuyas consecuencias colocaron gran parte del área central de México bajo control español, Hernán Cortés y sus hombres dirigieron su atención a tierras que los informantes les dijeron quedaban al sur y al este, en regiones distantes, donde llegaba la influencia azteca pero donde la autoridad azteca generalmente no predominaba. Chiapas y Guatemala eran dos de estas regiones, quizás mejor 


\section{CUADRO 4}

HABLANTES DE IDIOMAS MAYAS EN GUATEMALA, 1973-92

\begin{tabular}{lrrr} 
Grupo lingüístico & \multicolumn{3}{c}{$\begin{array}{c}\text { Número de hablantes } \\
(1980)\end{array}$} \\
\hline Achí & 58.000 & 50.000 & $(1992)$ \\
Akateko & - & 20.000 & 39.826 \\
Awakateko & 16.000 & 15.000 & 34.476 \\
Ch'orti' & 52.000 & 25.000 & 74.600 \\
Chuj & 29.000 & 30.000 & 85.002 \\
Ixil & 71.000 & 50.000 & 130.773 \\
Jakalteko (Popti') & 32.000 & 25.000 & 83.814 \\
K'iche' (Kichee') & 967.000 & 1.000 .000 & 1.842 .115 \\
Kaqchikel & 405.000 & 500.000 & 1.002 .790 \\
Mam & 644.000 & 500.000 & 1.094 .926 \\
Poqomam & 32.000 & 30.000 & 127.206 \\
Poqomchi' & 50.000 & 50.000 & 259.168 \\
Q'anjob'al & 112.000 & 100.000 & 205.670 \\
Q'eqchi' & 361.000 & 400.000 & 711.523 \\
Sakapulteko & 21.000 & 20.000 & 42.204 \\
Sipakapense & 3.000 & 3.000 & 5.944 \\
Tektiketo (Teko) & 2.500 & 3.000 & 4.755 \\
Tz'utujil & 80.000 & 80.000 & 156.333 \\
Uspanteko & 2.000 & 2.000 & 21.399 \\
& & &
\end{tabular}

Fuentes: Para 1973, véase Pamela Sheetz de Echerd, ed., Bibliografía del Instituto Lingüístico de Verano de Centroamérica (Ciudad de Guatemala: Instituto Lingüístico de Verano, 1983), págs. 4-7; para 1980, véase Francesc Ligorred, Lenguas indígenas de México y Centroamérica (Madrid: Editorial MAPFRE, 1992), págs. 220-23; y para 1992, véase Leopoldo Tzian, Mayas y Ladinos en cifras: El caso de Guatemala (Ciudad de Guatemala: Editorial Cholsamaj, 1994), 20-25. Tzian considera que el Achí es una variante del K'ich'e. Proporciona una cifra de 13.007 para los hablantes de Mopán y 1.783 para los hablantes de Itzaj. Los mopanes y los itzajes son grupos mayas de las tierras bajas.

conocidas en Tenochtitlán por la calidad del cacao, la cochinilla y las plumas de quetzal que producían. Cuando los españoles se aventuraron en estas partes, se enfrentaron a situaciones difíciles en las que las guerras de conquista había que hacerlas no contra un estado unido, bien integrado, sino contra naciones pendencieras, distintas unas de otras, acostumbradas durante mucho tiempo a guardarse resentimiento y agraviarse unas 
a otras. Bajo estas circunstancias, la conquista no sería ni repentina ni segura.

La expedición que Luis Marín encabezó a Chiapas, en febrero de 1524 , encontró allí varias sociedades bien organizadas, ninguna de ellas especialmente poderosa, pero todas capaces de valerse de lealtades locales resueltas. El pequeño grupo de Marín avanzó por la región zoque, la parte más occidental de Chiapas, sin ninguna dificultad. Los zoques, cuyo idioma los vincula más a los mixes que a los mayas, ocupaban entonces territorio situado en medio de la Cuenca de Grijalva. Río arriba, en el lugar de la actual Chiapa de Corzo, Marín peleó con los chiapanecos, grupo de origen no determinado. Después de la rendición de estos, Marín marchó con sus hombres hacia el corazón del altiplano central, donde lo esperaban pueblos mayas más apropiadamente definidos. Pasó por Zinacantán, antes de enfrentarse a fuerzas tzoltziles en Chamula. En lugar de ir hacia el este y hacia el sur en dirección a Guatemala, lo cual habría resultado en escaramuzas con comunidades tzeltales y tojolabales, Marín regresó hacia el norte, ruta a Tabasco. Su expedición, en general, tenía más que ver con un reconocimiento estratégico que con el establecimiento formal de dominio español. No fue sino hasta casi cuatro años después, época en la que Pedro Portocarrero y Diego de Mazariegos ya habían vuelto a entrar a Chiapas por diferentes direcciones y con ejércitos más grandes, cuando los pueblos mayas del altiplano central cayeron bajo un dominio español más efectivo. Su territorio fue inicialmente administrado como parte de Nueva España, a partir de entonces (1530-1821) como parte de Guatemala, salvo durante un período breve de cuatro años (1540-44) cuando Chiapa (como los españoles llamaban a la provincia del interior) se autogobernó. El núcleo del asentamiento español en Chiapas era Ciudad Real, el actual San Cristóbal de las Casas.

Poco antes de que Marín penetrara desde el norte, las fuerzas dirigidas por Pedro de Alvarado recorrieron el litoral de Soconusco, región situada por debajo de la Chiapa española, al sur de la Sierra Madre, rumbo a Guatemala. No encontraron ninguna resistencia apreciable a lo largo de la Costa del Pacífico. Sin embargo, después de subir al altiplano guatemalteco hubo varias batallas. Los principales oponentes fueron los k'iche's, después de cuya derrota los españoles tuvieron que enfrentarse a otros pueblos mayas, uno por uno, los mames, los ixiles y los ch'orti's, sólo tres de los muchos que había. Guerreros kaqchikeles pelearon al lado de los españoles, como en la conquista de los tzutujiles de Atitlán. La alianza kaqchikel, 
sin embargo, se debilitó después de escasos seis meses, cuando las excesivas demandas de tributo los hicieron organizar una rebelión que duró casi cuatro años. Los kaqchikeles nos dicen:

Luego Tunatiuh [Alvarado] les pidió dinero a los reyes. Quería que les dieron montones de metal, sus vasijas y coronas. Y como no se las trajesen inmediatamente, Tunatiuh se enojó con los reyes y les dijo: “¿Por que no me habéis traido el metal? Si no traéis con vosotros todo el dinero de las tribus, os quemaré y os ahorcaré," les dijo a los señores.

En seguida los sentenció Tunatiuh a pagar mil doscientos pesos de oro. Los reyes trataron de obtener una rebaja y se echaron a llorar, pero Tunatiuh no consintió y les dijo: "Conseguid el metal y traedlo dentro de cinco días. ¡Ay de vosotros si no lo traéis! ¡Yo conozco mi corazón! Así les dijo a los señores."

Ya se había entregado la mitad del dinero cuando nos escapamos .... Nosotros nos dispersamos bajo los árboles, bajo los bejucos ¡oh hijos míos! Todas nuestras tribus entraron en lucha con Tunatiuh .... Abrieron pozos y hoyos para que los caballos y sembraron estacas agudas para se mataran .... Muchos castellanos perecieron .... Fueron combatidos por la gente y siguieron haciendo una guerra prolongada. ${ }^{2}$

Algunos grupos mayas, los q'eqchi's y los uspantekos entre ellos, de hecho derrotaron temporalmente a los invasores, antes de sucumbir a actos de agresión posteriores mejor organizados. En una incursión, Portocarrero, responsable de los logros españoles contra los kaqchikeles en 1527, avanzó hacia el norte y hacia el occidente, atravesando Guatemala y luego dirigiéndose a Chiapas, donde se encontró con Mazariegos en Comitán. Este encuentro muy probablemente ocurrió en 1528; para esa época, quizás los pueblos mayas del altiplano central de Chiapas ya estuviesen subyugados, pero los seguidores de Alvarado todavía se hallaban en apuros en Guatemala. No fue sino hasta diez a viente años más tarde, en ciertas áreas mucho más tiempo, cuando los españoles sometieron a los indígenas de Guatemala. La resistencia maya hizo de la subyugación militar un asunto prolongado y sangriento.

La capacidad de los pueblos mayas para organizar ejércitos para impedir la intrusión española es un indicio importante de que sus tierras tenían poblaciones bastante grandes. Si persiste el debate en cuanto a cuántos indígenas precisamente estaban vivos cuando los españoles llegaron, menos controvertido es el hecho de que la conquista fue más o menos contemporánea con un proceso de despoblación que duró ya bien entrado el

2 Recinos, Adrián (traductor): Memorial de Sololá: Anales de los Cakchiqueles, Mexico: Fondo de Cultura Económica, 1950, págs. 128-131. 
siglo XVII y, en el caso de Chiapas, mucho más allá. El cuadro 5 indica el tamaño variable de los cálculos de contacto propuestos en varios estudios sobre Guatemala. De los cálculos representados, los propuestos por Denevan y por Lovell y Lutz (dos millones en cada caso) se relacionan con todo o una porción substancial del territorio nacional. Sanders y Murdy (de 500.000 a 800.000) sólo cubren el altiplano de Guatemala, mientras que Zamora (315.000) se ocupa exclusivamente de la mitad occidental del país. Solano (300.000) nunca define su orbita espacial claramente, pero sus cálculos incluyen un área enorme. Esto significa que se deben tener presentes las diferencias en extensión territorial cuando se hacen comparaciones entre los cálculos.

\section{CuAdro 5}

DESPOBLACIÓN INDÍGENA EN LA GUATEMALA DEL SIGLO XVI

\begin{tabular}{lrrrrr} 
Año & Denevan & Lovell y Lutz & Sanders y Murdy & Zamora & Solano \\
\hline hacia 1520 & 2.000 .000 & 2.000 .000 & $500-800.000$ & 315.000 & 300.000 \\
hacia 1550 & - & 427.850 & - & 121.000 & 157.000 \\
hacia 1575 & - & 236.540 & - & 75.000 & 148.000 \\
hacia 1600 & - & 133.280 & - & 64.000 & 195.000
\end{tabular}

Fuentes: Denevan, William M. (ed.): The Native Population of the Americas in 1492, Madison: University of Wisconsin Press, 1976, pág. 291; Lovell, W. George, y H. Lutz, Christopher: Demografía e imperio: Guía para la historia de la población de la América Central española, 1520-1821, Guatemala: Universidad de San Carlos, 2000, pág. 13; Sanders, William T., y Carson Murdy: "Population and Agricultural Adaptation in Highland Guatemala," en Carmack, Robert M.; Early, John D., y Lutz, Christopher H. (eds.): The Historical Demography of Highland Guatemala, Albany, New York: Institute for Mesoamerican Studies, 1982, pág. 32; de Solano, Francisco: Los mayas del siglo XVIII, Madrid: Ediciones Cultura Hispánica, 1974, págs. 62-96; y Zamora Acosta, Elías: "Conquista y crisis demográfica: La población indígena del occidente de Guatemala en el siglo XVI," Mesoamérica 6, 1983, págs. 291-328.

En Chiapas, nos encontramos con menos estudios sobre la demografía maya colonial, lo cual limita el examen a puntos esenciales. Afortunadamente, estos son proporcionados por la investigación sólida de Peter Gerhard, quien calcula que una población indígena alrededor de 275.000 al momento del contacto había disminuido a 70.000 en 1650, había aumentado a 72.000 en 1700 , había disminuido nuevamente en 1800 a 53,000, para sumar aproximadamente 58.000 en la época de la independencia (Cuadro 6). 
Así como, sin importar el número implicado, ahora existe un acuerdo general de que la despoblación indígena fue drástica, si no catastrófica, también así se reconoce que de la combinación de factores responsables por la disminución, la parte que jugaron las enfermedades epidémicas fue la más crucial. Los mayas del altiplano, como los pueblos indígenas desde Alaska hasta la Tierra del Fuego, no tenían inmunidades naturales contra una serie horrible de infecciones del Viejo Mundo. En consecuencia, se encontraban en una posición vulnerable cuando enfermedades tales como la viruela, el sarampión, las paperas y la peste, transferidas sin querer por conquistadores españoles y esclavos africanos, entraron en sus entornos de suelo virgen.

\section{CuAdRo 6}

LA POBLACIÓN INDÍGENA DE CHIAPAS Y SOCONUSCO, 1511-1821

\begin{tabular}{lrrrrrrrr} 
Provincia & \multicolumn{1}{c}{1511} & 1550 & 1600 & 1650 & 1700 & 1750 & 1800 & 1821 \\
\hline Chiapas & 275.000 & 125.000 & 85.000 & 70.000 & 72.000 & 65.000 & 53.000 & 58.000 \\
Soconusco & 80.000 & 7.000 & 6.600 & 4.000 & 2.700 & 4.650 & 4.200 & 4.000
\end{tabular}

Fuente: Gerhard, Peter: The Southeast Frontier of New Spain, Princeton, NJ: Princeton University Press, 1979, pág. 25.

Nuestro conocimiento del alcance de las enfermedades tiende a estar mejor desarrollado para Guatemala. Sin embargo, muchas de las enfermedades que se registraron allí también debe haber afectado a Chiapas. Hasta ocho epidemias masivas atacaron Guatemala entre 1519 y 1632, período en el que también se dieron episodios más localizados. Brotes de enfermedad a menudo provocaban otros escenarios de crisis, ya que la mala salud impedía sembrar las milpas, lo que a su vez provocaba escasez de comida y hambrunas. En el Memorial de Sololá se encuentran numerosas referencias a brotes de enfermedad, ninguna de ellas más gráfica que la descripción de una peste que de hecho llegó a Guatemala antes de que llegaran los propios españoles:

He aquí que durante el quinto año [1519-1520] apareció la peste ¡oh hijos míos! Primero se enfermaban de tos, padecían de sangre de narices y de mal de orina. Fué verdaderamente terrible el número de muertos que hubo en esa época .... Era terrible en verdad el número de muertes entre la gente. De ninguna manera podía la gente contener la enfermedad. 
Grande era la corrupción de los muertos. Después de haber sucumbido nuestros padres y abuelos, la mitad de la gente huyó hacia los campos. Los perros y los buitres devoraban los cadaveres. La mortandad era terrible. Murieron vuestros abuelos y junto con ellos murieron el hijo del rey y sus hermanos y parientes. Así fué como nostros quedamos huérfanos ¡oh hijos míos! Así quedamos cuando éramos jóvenes. Todos quedamos así. ${ }^{3}$

Por consiguiente, los resultados inmediatos de la intrusión española fueron la guerra, los brotes de enfermedad y el colapso demográfico. Después del trauma de estos trastornos, vino el oneroso cargo de estar sometido al yugo colonial, estatus que exigía expresiones de lealtad y obligaciones muy diferentes a las observadas anteriormente. Se introdujeron varias instituciones por medio de las cuales se implementarían los proyectos y las expectativas imperiales. Dos instituciones claves eran la encomienda y la congregación.

La historia de la encomienda es compleja, pero durante los siglos XVI y XVII fue un mecanismo por medio del cual españoles o criollos recibían tributo en trabajo, artículos o dinero de los indígenas que estaban a su cargo. Las encomiendas no eran concesiones de tierra sino, más bien, derechos para disfrutar de los frutos de lo que la tierra y su gente podían proporcionar, ya sea artículos preciados tales como oro, plata, sal y cacao, o productos básicos como maíz y frijoles. Los derechos llevaban consigo ciertas obligaciones, entre ellas cuidar de que los indígenas recibieran instrucción en los principios y la práctica de la Santa Fe Católica, obligación que pocos encomenderos consideraban conveniente cumplir.

Las primeras encomiendas a menudo llevaban consigo la adjudicación de cantidades substanciales de tributo. Los encomenderos al principio gozaban de considerable poder como recipientes de tributo, pero el papel de la Corona en relación con la encomienda fue un papel de restricción. Al final, la Corona tomó medidas para desmantelar los privilegios — poniendo restricciones a las disposiciones laborales, por ejemplo, y limitando la herencia más allá de una o dos generaciones- para impedir que incluso los encomenderos más emprendedores se convirtieran en el equivalente de señores feudales. De especial importancia a este respecto fueron las reformas realizadas entre 1548 y 1555, cuando Alonso López de Cerrato fue

3 Recinos, A.: Memorial de Sololá..., págs. 119-120. Véase también Lovell, W. George: "Enfermedad y despoblación en Guatemala, 1519-1632," en Cook, Noble David, y Lovell, W. George (editores): "Juicios secretos de Dios": Epidemias y despoblación en Hispanoamérica colonial, Quito: Ediciones Abya-Yala, 2000, págs. 89-118. 
presidente de la Audiencia de Guatemala, corte cuyos miembros eran nombrados por la Corona y tenían a su cargo el gobierno diario de la extensa jurisdicción que se extendía desde Chiapas hasta Costa Rica. Cuando fue abolida por el régimen borbónico en el siglo XVIII, la encomienda no representaba más que un tipo modesto de pensión.

Los estudios de la encomienda en la Audiencia de Guatemala normalmente toman los años de Cerrato como punto de partida. Esta tendencia es comprensible, y la explica mejor el hecho de que nuestra lista de encomiendas más completa y temprana - quién las tenía, qué clases de tributo recibían, que comunidades estaban implicadas - pertenece a la presidencia de Cerrato. Las acciones de Cerrato, especialmente su liberación de los esclavos indígenas y su papel pionero en tratar de poner en vigor las Nuevas Leyes de 1542, ciertamente merecen reconocimiento. Sin embargo, centrarse en Cerrato ha servido para que no nos interesemos en examinar la encomienda cuando la institución (desde el punto de vista español) era más remunerativa y (desde una perspectiva indígena) estaba en su punto de mayor explotación - los primeros veinte años después de la conquista, cuando los encomenderos mismos fijaban las cuotas de tributo, cuando la mano moderadora del gobierno no existía. Un correctivo muy necesitado lo proporciona Wendy Kramer, quien concluye que "lejos de ser el punto de partida de la encomienda en Guatemala, o de reflejar innovaciones recientes realizadas por el nuevo presidente, la [tasación] de Cerrato refleja las circunstancias y las lealtades de seis hombres diferentes, influenciados por, y respondiendo a, las vicisitudes de once gobiernos diferentes." ${ }^{4}$ Estos seis hombres y sus once gobiernos (Cuadro 7) a menudo asignaban o intercambiaban, confirmaban o quitaban privilegios de encomienda, cada una de los cuales valía miles de pesos anualmente.

Uno puede hacerse una idea de la recompensa o la carga en juego, y obtener una medida concreta de la diferencia entre la época anterior a Cerrato y la época de Cerrato, examinando los detalles de una encomienda. El caso de Huehuetenango proporciona datos útiles sobre las obligaciones de encomienda y aclara el proceso de cambio a través del tiempo.

Un aguerrido español de nombre Juan de Espinar tuvo Huehuetenango en encomienda desde 1525 hasta su muerte en la década de 1560, con una interrupción de diez a doce meses (1530-31), cuando el privilegio pasó a Francisco de Zurrilla. Durante más de treinta años, una mezcla de

4 Kramer, Wendy: Encomienda Politics in Early Colonial Guatemala, 1524-1544: Dividing the Spoils, Boulder, Colorado: Westview Press, 1994, pág. 236. 
persistencia y habilidad política, acompañada de dureza que a veces se convertía en pura crueldad, convirtió a Espinar en el amo de Huehuetenango. Tenía asimismo instintos empresariales, controlando la venta de tributo indígena y desarrollando una elaborada infraestructura de actividades mineras y agrícolas. Inició las operaciones mineras después de darse cuenta de que, a unos diez kilómetros al sur de Huehuetenango, al lado del río Malacatán, se podían explotar placeres de oro. La buena fortuna para Espinar resultó una maldición para los indígenas que controlaba. En documentos preparados más tarde para litigio, Espinar afirmó que cuando Huehuetenango estaba en su apogeo, él ganaba aproximadamente 9.000 pesos cada año por su participación en la minería y otros 3.000 pesos por sus transacciones agrícolas.

\section{Cuadro 7}

CONCESIONES DE ENCOMIENDA EN GUATEMALA, 1524-48

\begin{tabular}{lccc}
$\begin{array}{c}\text { Gobernadores, tenientes de gobernador } \\
\text { y gobernadores interinos }\end{array}$ & $\begin{array}{c}\text { Número de } \\
\text { concesiones }\end{array}$ & $\begin{array}{c}\text { Número de } \\
\text { encomenderos }\end{array}$ \\
\hline Pedro de Alvarado & $1524-26$ & 25 & 21 \\
Jorge de Alvarado & $1527-29$ & 86 & 56 \\
Francisco de Orduña & $1529-30$ & 12 & 11 \\
Pedro de Alvarado & $1530-33$ & 77 & 45 \\
Jorge de Alvarado & $1534-35$ & 7 & 6 \\
Pedro de Alvarado & $1535-36$ & 18 & 10 \\
Alonso de Maldonado & $1536-39$ & 12 & 8 \\
Pedro de Alvarado & $1539-40$ & 7 & 3 \\
Francisco de la Cueva & $1540-41$ & 13 & 5 \\
Franciso Marroquín & & & \\
$\quad$ y Francisco de la Cueva & $1541-42$ & 18 & 16 \\
Alonso de Maldonado & $1542-48$ & 30 & 20
\end{tabular}

Fuente: Kramer, Wendy: Encomienda Politics in Early Colonial Guatemalal, 1524-1544: Dividing the Spoils, Boulder, Colorado: Westview Press, 1994, pág. 245.

Espinar vivió lo suficiente para sentir los efectos de la disminución de la población de Huehuetenango a una fracción de lo que había sido cuando inicialmente se le otorgó la encomienda (Cuadro 8). Un factor no relacionado con la enfermedad pero que afectó el tamaño de la población fue 
que, entre 1525 y 1530, Espinar no sólo tenía Huehuetenango mismo sino también un puñado de pueblos circundantes, cuyo derecho perdió posteriormente, cuando fueron adjudicados a otros españoles. El hecho de perder, durante un año, la encomienda de Huehuetenango a favor de Zurilla provocó una demanda en la que Espinar puso por escrito el botín del que se le había privado. Su deseo de conservar la encomienda era perfectamente comprensible, ya que la pérdida era considerable: los artículos enumerados en la columna central del Cuadro 9 habrían generado buenos ingresos al ser vendidos en el mercado. Además, los suministros de servicio sólo en las minas representaban entre 43.200 y 72.000 días de trabajo al año por parte de los hombres y 10,800 días de trabajo al año por parte de las mujeres. La columna de la derecha del cuadro 9 refleja la encomienda reducida y domeñada de Huehuetenango, después de las reformas de Cerrato. Aunque las ganancias a mediados de siglo eran notablemente menores, Espinar aún podía consolarse sabiendo que tenía la undécima encomienda más grande en toda Guatemala, no incluyendo aquellas encomiendas en las que el tributo se pagaba a la Corona.

\section{CuAdro 8}

\section{LA POBLACIÓN TRIBUTARIA DE HUEHUETENANGO Y PUEBLOS SUJETOS, 1530-31 y 1549}

\begin{tabular}{lcc} 
Cabecera/pueblo sujeto & $1530-31$ & 1549 \\
\hline Huehuetenango (incluye Chiantla) & $3.000-3.500$ & 500 \\
Santiago Chimaltenango (Chimbal, Chinbal) & 500 & 35 \\
San Juan Atitán (Atitán) & - & - \\
San Pedro Necta (Niquitlán, Niquetla) & 200 & 20
\end{tabular}

Fuente: Kramer, Wendy, Lovell, W. George, y Lutz, Christopher H.: "Fire in the Mountains: Juan de Espinar and the Indians of Huehuetenango, 1525-1560," en Thomas, David Hurst (ed.): Columbian Consequences, vol. 3, Washington, DC: Smithsonian Institution, 1991, pág. 272.

Las encomiendas abarcaban, en grado espacial variable, una o más comunidades que los españoles llamaban pueblos de indios, con el significado municipal de lugar central y región circundante, áreas segregadas donde (en teoría) los no indígenas no podían establecerse. Cuando llegaron, los españoles observaron que, morfológicamente, los asentamientos mayas 
CuAdro 9

OBLIGACIONES DE ENCOMIENDA EN HUEHUETENANGO, 1530-31 Y 1549

\begin{tabular}{|c|c|c|}
\hline Artículo o servic & $1530-31$ & 1549 \\
\hline Ropa & $\begin{array}{l}800 \text { mantas } \\
400 \text { masteles } \\
400 \text { xicoles } \\
400 \text { huipiles } \\
400 \text { naguas } \\
400 \text { cutaras }\end{array}$ & 300 mantas \\
\hline Alimentos & $\begin{array}{l}\text { Cantidades no especificadas de } \\
\text { maíz, frijol, chile y sal } \\
\text { 108-126 jarras grandes de miel }\end{array}$ & $\begin{array}{l}\text { Maíz ( } 1 \text { sementera de } 15 \text { fanegas) } \\
\text { Frijoles ( } 1 \text { sementera de } 5 \text { fane- } \\
\text { gas) } \\
100 \text { cargas de agí } \\
100 \text { panes de sal }\end{array}$ \\
\hline Aves & 2,268 gallinas & 12 docenas de gallinas \\
\hline Otros artículos & 400 petates & $\begin{array}{l}1 \text { sementera de } 4 \text { fanegas de algo- } \\
\text { dón }\end{array}$ \\
\hline \multirow[t]{3}{*}{ Trabajo } & $\begin{array}{l}40 \text { indios de servicio, enviados a } \\
\text { Santiago de Guatemala en turnos } \\
\text { de veinte días todo el año }\end{array}$ & 6 indios de servicio \\
\hline & $\begin{array}{l}\text { 120-200 indios de servicio, envia- } \\
\text { dos a trabajar en las minas de oro } \\
\text { en turnos de veinte días todo el } \\
\text { año }\end{array}$ & \\
\hline & $\begin{array}{l}30 \text { indias de servicio, enviadas a } \\
\text { las minas de oro cada día para } \\
\text { hacer tortillas y preparar comida }\end{array}$ & \\
\hline Esclavos & $\begin{array}{l}80 \text { hombres y } 40 \text { mujeres que tra- } \\
\text { bajaban en las minas de oro }\end{array}$ & \\
\hline
\end{tabular}

Fuente: Kramer, Wendy; Lovell, W. George, y Lutz, Christopher H.: "Fire in the Mountains... Columbian Consequences, vol. 3, Washington, DC: Smithsonian Institution, 1991, págs. 274-75. 
eran más dispersos que nucleados, y que la poca urbanización que se había desarrollado estaba restringida a lugares altos defensivos, de ninguna manera propicios para una administración eficiente. La política de la congregación fue concebida para solucionar esta anarquía, y los pueblos de indios fueron el resultado de su implementación.

De acuerdo a como fue promulgada por la ley, la congregación era un medio a través del cual los indígenas que vivían en grupos aislados serían unidos, convertidos al cristianismo y moldeados en comunidades armoniosas, con recursos que reflejaban las nociones imperiales de vida organizada y civilizada. A la Iglesia, especialmente a los miembros de las órdenes franciscana y dominica, le tocó la difícil tarea de hacer bajar a las familias indígenas de las montañas y reasentarlas en pueblos construidos alrededor de un sitio católico de culto. La orden de misionizar, y el fundamento detrás de ella, está expresada claramente en una real cédula, promulgada el 21 de marzo de 1551:

Con mucho cuidado y particular atención, se ha procurado siempre interponer los medios más convenientes para que los indios sean instruidos en la Santa Fe Católica y Ley Evangélica, y olvidando los errores de sus antiguos ritos y ceremonias vivan en concierto y policía, y para que esto se executasse con mejor acierto se juntaron diversas vezes los de nuestro Consejo de Indias y otras personas religiosas, y congregaron los prelados de Nueva España el año de 1546 ... los cuales con deseo de acertar en servicio de Dios, y nuestro, resolvieron que los indios fuessen reducidos a pueblos y no viviessen divididos y separados por las sierras y montes, privándose de todo beneficio espiritual y temporal, sin socorro de nuestros ministros, y del que obligan las necesidades humanas que deben dar unos hombres a otros. Y por haverse reconocido la conveniencia de esta resolución por diferentes órdenes de los señores reyes nuestros predecesores, fue encargado, y mandado a los virreyes, presidentes y gobernadores que con mucha templanza y moderación executassen la reducción, población y doctrina de los indios. ${ }^{5}$

En el Memorial de Sololá tenemos una perspectiva maya de los eventos:

[L]legaron aquí ... nuestros Padres de Santo Domingo, Fray Pedro Angulo y Fray Juan de Torres. Llegaron de México el día 12 Batz [10 de febrero 1542]. Nuestra instrucción comenzó por medio de los Padres de Santo Domingo. Luego salió la Doctrina en nuestra lengua. Nuestros padres, Fray Pedro y Fray Juan, fueron los primeros que nos predicaron la palabra de Dios. Hasta entonces no conocíamos la pala-

5 Libro VI, Título III, Recopilación de las leyes de los reynos de las Indias, 3 tomos, Madrid: Ediciones Cultura Hispánica, 1973, III, pág. 198. 
bra ni los mandamientos de Dios; habíamos vivido en las tinieblas. Nadie nos había predicado la palabra de Dios.

En el quinto mes del sexto año desde que comenzó nuestra instrucción en la palabra de Nuestro Señor Dios, se agruparon las casas .... Entonces llegó la gente desde las cuevas y los barrancos. El día 7 Caok [30 de Octubre de 1547] se estableció esta ciudad [Sololá] y allí estuvimos todas las tribus. ${ }^{6}$

La retórica de la congregación pertenece mucho a lo que Carlos Fuentes llama el "país legal," una ficción colonial en marcado desacuerdo con el "país real" que llegó a existir.? En la visión global de imperio, pocas empresas se desviaron tan dramáticamente de la intención original como la congregación, impulsando a los observadores contemporáneos a expresar indignación, asombro y desesperación de que un plan tan grandioso pudiera convertirse en tan poco. La congregación dejó su marca en el entorno en una fecha temprana. De hecho, los pueblos de indios creados por el clero regular y secular en el transcurso del siglo XVI (Cuadro 10) persisten actualmente como municipios, entidades sociales que los antropólogos han considerado las unidades claves para definir la vida comunitaria maya. Sin embargo, ni bien los españoles habían reasentado a los indígenas donde los primeros consideraban adecuado, cuando un gran número de los últimos regresaron a las montañas de donde ellos y sus familias habían sido sacados. ¿Por qué sucedió esto? ¿Qué causó que se aflojara el control de la congregación?

\section{CUADRo 10}

\section{PUEBLOS DE INDIOS FUNDADOS EN EL SIGLO XVI POR EL CLERO REGULAR Y SECULAR}

$\begin{array}{lcc}\text { Tipo de clero } & \text { Pueblos fundados hacia } 1555 & \text { Pueblos fundados hacia } 1600 \\ \text { Dominicos } & 47 & 82 \\ \text { Franciscanos } & 37 & 108 \\ \text { Mercedarios } & 6 & 42 \\ \text { Clero secular } & 5(?) & 104 \\ \text { TOTAL } & 95 & 336\end{array}$

Fuente: Adriaan C. van Oss, Catholic Colonialism: A Parish History of Guatemala, 1524-1821 (Cambridge: Cambridge University Press, 1986), pág. 43.

6 Recinos, A.: Memorial de Sololá..., págs. 139-140.

7 Fuentes, Carlos: Latin America: At War with the Past, Toronto: CBC Enterprises, 1985, pág. 29. 
En primer lugar, la congregación fue realizada no por persuasión sino por la fuerza. El hecho de que familias enteras fueran trasladadas, en contra de su voluntad, de un lado a otro hacía poco probable que los miembros que consideraban la experiencia desagradable, si no odiosa, permanecieran en el mismo sitio. Repetidas veces los indígenas huyeron a las áreas rurales para escapar de la continua explotación que sufrían mientras residían en un pueblo o en sus cercanías. Allí podían estar libres de la obligación de dar tributo, proporcionar mano de obra, trabajar en los caminos locales o la iglesia parroquial y servir de cargadores humanos. El refugio de las montañas también se buscaba cuando atacaba la enfermedad, cuya brote en los pueblos de indios a menudo causaba mayor pérdida de vidas por causa de hacinamiento humano que la dura subsistencia en los cerros. Además, la forma en que los mayas cultivaban sus milpas normalmente se hacía mejor viviendo no en centros grandes y aglomerados, sino en grupos pequeños y dispersos.

A continuación está la cuestión de la fricción interconfesional y el despliegue de recursos espirituales. Junto con los mercedarios, un tercer grupo menos dominante en la empresa misionera, los dominicos y los franciscanos libraban lo que Adriaan van Oss llama una "disputa territorial," mientras eran impulsados simultáneamente por la llamada sublime de la congregación. Las dos órdenes más grandes y poderosas crearon, cada una, una esfera de influencia relativa a la capital de Santiago de Guatemala, la actual Antigua Guatemala. Los dominicos se trasladaron al lejano norte y occidente, y eran responsables de una región inmensa que se extendía desde Verapaz, atravesaba la Sierra de Chuacús y la Sierra de los Cuchumatanes, y llegaba hasta Chiapas. Los franciscanos optaron por una ronda central más manejable, dentro de un radio de cincuenta kilómetros alrededor del Lago de Atitlán. Los pueblos de indios establecidos en los confines de sus jurisdicciones eran defendidos celosamente por ambas órdenes contra la invasión rival. Las disputas entre ellos desviaron energía de la preocupación apremiante de la conversión indígena y se volvieron tan agotadoras que el 22 de enero de 1556 se dio una real cédula en la que se ordenaba a los frailes, acusados de "baja ambición" y de "proferir insultos," que resolvieran sus diferencias y se comportaran de una manera más digna y cristiana. $^{8}$

8 Van Oss, Adriaan C.: Catholic Colonialism: A Parish History of Guatemala, 1524-1821, Cambridge: Cambridge University Press, 1986, págs. 35-36. 
Tal comportamiento, a los ojos de la Corona, daba mal ejemplo y tenía poco sentido práctico, ya que los frailes eran pocos y sus responsabilidades muchas. De hecho, durante toda la época colonial menos de mil misioneros llegaron a propagar la fe entre los mayas de Guatemala. Las autoridades civiles reconocían bien la ardua batalla que sus asociados religiosos afrontaban diariamente: dos funcionarios de la Corona, Antonio Rodríguez de Quesada y Pedro Ramírez de Quiñones, abiertamente reconocieron que "en esta tierra hay mucha falta de religiosos." $\mathrm{A}$ mediados del siglo XVI, los dominicos estaban tan agobiados de obligaciones que les cedieron a los mercedarios el área que se prolonga hacia el sur, desde Huehuetenango hasta la frontera con Soconusco, una elección más aceptable para los dominicos que sus adversarios franciscanos. Por su parte, ya en 1552 los franciscanos habían pedido permiso a la Corona para asumir la responsabilidad de establecer misiones en territorio dominico, "pues que los padres de Santo Domingo no lo hagan."10 Sin embargo, la hegemonía de los dominicos prevaleció en Chiapas. En el otro extremo de la región, al sur y al este de Santiago, ninguna de las tres órdenes estableció una presencia significativa, dejando el "oriente" guatemalteco en las manos proletizadoras del clero secular menos experimentado.

En términos de jurisdicción misionera, la división entre un oriente "secular" y un occidente "regular" es importante reconocerla. Las divisiones eclesiásticas, sin embargo, sólo sirven para subrayar otro proceso más profundo, un proceso de regionalización mejor articulado por Murdo MacLeod en su magnum opus sobre la América Central española. ${ }^{11}$

MacLeod argumenta que la explotación de la base de recursos guatemaltecos funcionaba diferencialmente, de tal manera que la atención española se centraba en la costa del Pacífico rica en cacao y en las tierras templadas situadas al sur y al este de la capital, donde se podía cultivar índigo, apacentar ganado y recoger dos o incluso tres cosechas de maíz cada año. Los españoles consideraban mucho menos atractiva la tierra fría del altiplano, situada al norte y al oeste de Santiago — de acceso más difícil y con pocas opciones empresariales. Por consiguiente, su interés en el norte y el occidente nunca fue tan intenso como en el sur y el oriente. Cuando las

9 Archivo General de Indias (en adelante AGI), Audiencia de Guatemala (en adelante AG), 9A, Antonio Rodríguez de Quesada y Pedro Ramírez de Quiñones a la Corona, 25 de mayo de 1555.

10 AGI, AG 168, Fray Juan de Mansilla a la Corona, 30 de enero de 1552.

11 MacLeod, Murdo, J.: Historia socio-económica de la América Central española, 15201720, Guatemala: Editorial Piedra Santa, 1980. 
actitudes españolas relacionadas con el valor de la tierra se traducían en miles de acciones individuales, resultaban en una experiencia colonial notablemente distinta.

Al sur y al este de Santiago de Guatemala, donde se invadieron más comunidades nativas, la asimilación cultural y biológica avanzó a un paso más rápido. En el oriente, como también en el vecino El Salvador, los españoles y los africanos se mezclaron con los indígenas y crearon un entorno predominantemente mestizo o ladino. Siempre se podían encontrar en estas partes grupos nativos, ya sea mayas desplazados del altiplano o pipiles autóctonos, hablantes de nahua. Después de todo, la mano de obra indígena, barata y explotada, era la base de la prosperidad económica, la cual fluctuaba en ciclos de auge y quiebra, mientras que la búsqueda de un cultivo comercial exitoso vio al cacao y al índigo ceder el paso a la cochinilla y a la zarzaparilla y, finalmente, al café y los bananos en nuestros días. Sin embargo, al norte y el oeste de la capital, donde las oportunidades de enriquecimiento eran menos y donde pocos españoles estaban dispuestos a establecerse, los pueblos mayas soportaron con mayor resistencia el ataque de aculturación, conservando gran parte de su tierra, reteniendo principios de organización comunitaria y preservando un sentido de identidad que era decididamente suyo. Los idiomas mayas se mantuvieron vivos, así como las costumbres mayas de adorar a los dioses. Las tareas diarias y el ciclo de las estaciones seguían un ritmo maya, no uno español. Incluso el tiempo mismo, los días y los meses que formaban un año, avanzaban con un pulso maya. Cuando, existencialmente, se sitúa la congregación dentro de este panorama, la reacción maya a ella adopta una dinámica formativa y vital.

Condenados por la geografía a vivir en una región atrasada en el esquema español de imperio, los mayas moldearon para ellos mismos una cultura de refugio en la que las características e instituciones hispánicas fueron absorbidas y mezcladas con las nativas, a menudo de maneras elaboradas que desconcertaban a, se burlaban de, y al final erosionaron la autoridad colonial. La periodización es algo difícil. Seguramente ya en el siglo XVII, los patrones de costumbres híbridas eran muy evidentes, pero la tendencia había comenzado mucho antes. El reconocimiento de que todo marchaba bastante mal, que la congregación no estaba desarrollándose de acuerdo con el plan, provocó las siguientes observaciones de Pedro Ramírez de Quiñones, redactadas con frustración en una carta al Consejo de Indias: 
En los pueblos de los naturales hay gran desorden en lo que toca a la policía. Hay muy poco orden entre ellos, ni instrucción. Pecados públicos hay entre ellos muy grandes. Y lo más es que son sin castigo, porque no viene a noticia de la audiencia. En los más pueblos de indios viven cada uno como quiere o como puede y como la audiencia no puede enviar visitadores no pueden cumplir de visitar la décima parte del distrito. ${ }^{12}$

Incluso cuando los indígenas desplazados por la congregación elegían permanecer dentro de su abrazo espacial, a menudo se reagrupaban en el pueblo, o cerca de éste, siguiendo linajes domésticos de preconquista que los españoles llamaban parcialidades. Éstas eran unidades sociales de gran antigüedad, organizadas como clanes patrilineales o afiliaciones localizadas de parentesco, y normalmente asociadas con extensiones particulares de tierra. Como los misioneros desconocían la naturaleza discreta de las parcialidades, a menudo varias de ellas eran amontonadas para formar, en teoría, una sola comunidad indígena. Sin embargo, una vez reunidas alrededor de un nuevo centro, las parcialidades conservaban su identidad aborigen al continuar funcionando social y económicamente como componentes separados, en lugar de unirse para formar un cuerpo corporativo. Lejos de ser las entidades plácidas y homogéneas que conjura la legislación imperial, muchos pueblos de indios llegaron a ser un mosaico de parcialidades que se tocaban pero no se penetraban, coexistían pero no siempre cooperaban. En el Corregimiento de Totonicapán, por ejemplo, nueve pueblos de indios comprendían más de treinta parcialidades, cada una de las cuales era tasada individualmente para propósitos del pago de tributo (Cuadro 11) a finales del siglo XVII. Uno de estos pueblos, Sacapulas, incluso logró arreglar que la tierra fuera tenida y cultivada por parcialidad, como lo hacían otros pueblos de indios. Las parcialidades también podían estar correlacionadas con cofradías específicas, introducidas originalmente para el culto de un santo favorecido pero que, con el tiempo, llegaron a servir de útil cobertura cristiana para expresiones más sospechosas.

Si el compromiso residencial con la congregación resultó en cierto grado de improvisación, el abandono de los pueblos condujo a aberraciones manifiestas. De nuevo, la decandencia empezó tempranamente. Sacapulas, por ejemplo, tal vez no haya cristalizado precisamente como sus fundadores dominicos imaginaron en un principio, pero una vez que su convento había sido establecido en la ribera sur del río Negro, sí se formó una comunidad bien definida a su alrededor. Una cuestión totalmente distinta era el área rural remota, como revela vívidamente el relato de dos dedicados frailes.

12 AGI, AG 94, Pedro Ramírez de Quiñones al Consejo de Indias, 20 de mayo de 1556. 
CuAdro 11

PUEBLOS Y PARCIALIDADES EN EL CORREGIMIENTO

DE TOTONICAPÁN, C. 1686

Pueblo de indios

Parcialidades

Tributarios

Aguacatán

Aguacatán

Chalchitán

64

Comitán

91

Chajul

Box

4

Ilom

3

San Gaspar

Uncavav

30

San Marcos

64

Chiquimula

Santa María

24

Cotzal

Chil

$120-29$

$\mathrm{Cul}$

10

San Juan

28

Cunén

Magdalena

20-29*

San Francisco

6

Momostenango

Santa Catalina

114

Santa Ana

50

Santa Isabel

40

Santiago

38

Cuchil

224

Nebaj

Osolotén

26

Salquil

16

Santa María

$10-19 *$

Acunil

76

Sacapulas

Bechauzar

48

Cuatlán

42

Magdalena

84

Tulteca

Pal

San Gerónimo

San Marcos

San Francisco

* Este manuscrito sufrió serios daños en un incendio ocurrido en el archivo, a principios del siglo pasado. Las cifras marcadas con un asterisco indican que el último número estaba tan quemado que no era legible o se ha desintegrado completamente. Por lo tanto, en cuatro casos, sólo se puede hacer un cálculo de la población de la parcialidad que pagaba tributo.

Fuente: Archivo General de Indias, Contaduría 815. 
Escribiendo al Rey desde el convento de Sacapulas, el 6 de diciembre de 1555, Tomás de Cárdenas y Juan de Torres hablan de los tremendos obstáculos que impedían la congregación efectiva. Mencionan, en primer lugar, las dificultades impuestas por el entorno físico, declarando no sin justificación que "aquel pedazo de sierra es de lo más fragoso y aspero que hay por estas tierras." Mientras la atravesaban, Cárdenas y Torres se habían topado con "poblaciones de hasta ocho y seis y aun de cuatro casas o chozas, metidos y escondidos por las barrancas donde hasta uno de nosotros, ningún otro español aportó.” Los frailes se lamentan de que, a lo largo de su caminata, descubrieron "muy grande copia de ídolos, no sólo escondidos pero en públicas casas como los que tenían antes que fuesen baptizados." Los indígenas, argumentan, pueblan tales lugares desolados para que "nadie aportaba allá que les pudiese perjudicar ni estorbar su mal vivir." Las familias que habían encontrado viviendo de esa manera, afirman los dominicos con cierto alivio, "ahora, estando juntos, ellos tendrán menos oportunidad para idolatrar y nosotros mucha más para los visitar." Reasentados de esta manera, los indígenas pueden ser "doctrinados no sólo en las cosas de Nuestra Santa Fe pero también en las de la humana policía." Para los que podrían lamentarse de que la congregación se hacía de manera involuntaria, que trasladaba familias de un lugar a otro en contra de su voluntad, Cárdenas y Torres afirmaban que "no hay enfermo a quien las medicinas no sepan mal." En este sentido, los indígenas "son como niños, y como tales cumple hacer no lo que más les agrada sino lo que más les cumple." Si a veces el tono de los frailes es sobrio y paternalista, el mismo también es conmovedor y prudente. Los dos dominicos captan muy perceptivamente por qué las familias mayas podrían resistirse a la congregación cuando señalan: "Entre todos estos indios ninguno hay que quiera dejar la casilla que su padre le dejó, ni salirse de una pestilencial barranca o de entre unos rescos inaccesibles, porque allí tienen los huesos de sus abuelos."13

Palabras solemnes, expresadas con un sentimiento de presagio que no tardó en resultar bien fundado. Unos años después de que Cárdenas y Torres se dirigieran al Rey, los principales y caciques de Santiago Atitlán

13 AGI, AG 168, Tomás de Cárdenas y Juan de Torres a la Corona, 6 de diciembre de 1555. Para amplia discusión sobre los éxitos y los fracasos de la pólitica de la congregación, véase Lovell, W. George: Conquista y cambio cultural: La Sierra de los Cuchumatanes de Guatemala, 1500-1821, Antigua Guatemala y South Woodstock, Vermont: Centro de Investigaciones Regionales de Mesoamérica y Plumsock Mesoamerican Studies, 1990, págs. 77-99. 
observaran que "hay en nuestras estancias algunos indios rebeldes que quieren estar fuera de nuestra subyugación y no obedecer nuestros mandamientos en recoger el tributo y otras cosas tocantes." ${ }^{14}$ Aun cerca de la ciudad capital abundaba la deserción; en 1575 los indígenas de los alrededores de Santiago "se iban de un lugar a otro y se escondian y ausentaban muchos" para evitar ser obligados a proporcionar su propio tributo y pagar aquella parte que se considera que sus familiares difuntos todavía deben. ${ }^{15}$ En la misma época, en Verapaz, se informó que parcialidades y familias enteras se marchaban para vivir en las montañas. Dos pueblos de indios, Santa Catalina y Zulbén, habían sido abandonados casi completamente en 1579, sólo cinco años después de que el propio obispo de Verapaz hubiera supervisado el proceso de congregación. En Santa María Cahabón, indígenas ya bautizados abandonaron su pueblo para unirse "de secreto" con "muchos indios infieles que [se] llaman los manchés."16

Un siglo más tarde, después de que el obispo de Guatemala, Andrés de las Navas, hubiera recorrido por segunda vez su jurisdicción y escuchado, de boca de los curas, noticias de huida, anarquía, idolatría y evasión de impuestos, preparó un expediente que deja poca duda acerca de cuán extendida estaba la desobediencia indígena. Fuera de San Juan Sacatepéquez, segun el Obispo, existía "una sinagoga en un sitio llamado El Pajuiú, donde hace más de viente años que los indios que allí viven ni oyen misas ni confiessen, con pretexto de milperias." Otros pueblos de indios centralmente ubicados —Chimaltenango, Parrámos, Patzizía, Patzún, San Andrés Iztapa, San Martín Jilotepeque, Sumpango y Tecpán entre ellos- provocaron también la ira del Obispo. La reincidencia religiosa era sólo un ejemplo de la desobediencia que le preocupaba. En Comalapa, Las Navas habla de "sahorines y contadores de días," declarando con aversión: "Y cuando los religiosos les predican en la Iglesia y les amonesten que dejen las supersticiones y idolatrías, después que salen de la Iglesia unos con otros dicen que por que han de dejar lo de sus abuelos y antepasados."

Tales actitudes entre los indígenas que vivían cerca de Santiago, sólo se exacerbaban lejos de la capital, en ninguna parte más notable que en San

14 AGI, AG 53, Principales y Caciques de [Santiago] Atitlán a la Corona, 1 de febrero de 1571.

15 AGI, AG 10, Presidente Pedro de Villalobo al Rey, 5 de octubre de 1575 y Eugenio de Salazar al Rey, 15 de marzo de 1578.

16 AGI, AG 10, Obispo de Verapaz al Rey, 1581, y AGI, AG 163, Obispo de Verapaz a la Corona, 20 de marzo de 1600. 
Mateo Ixtatán. Allí, en un rincón casí olvidado en la Sierra de los Cuchumatanes, "tierra más ágria y aspera en todo el mundo," Fray Alonso de León anotó que le habían informado "que no estaban puestas en tasación unas ochenta familias," lo cual significaba no sólo que "Su Majestad pierde mucho de sus haveres reales," sino también que "todos estos ocultos no oyen misa, ni se confiessan." La relación entre padre e hijo, declaró De León, era una en la que "no les enseñan más que hacer milpas y vivir todo el día como bárbaros en el monte.” Temía que nunca arraigarían comportamiento civilizado, ya que los indígenas de San Mateo "viven con guerras civiles todo el año, unos contra otro.” Lo que más consternaba a Fray Alonso era que los indígenas habían decidido construir "una hermita, sin más autoridad que la suya, fuera del pueblo en el monte, en el mismo lugar que fue el sacrificadero antiguo de su gentilidad y barbarismo." La hermita se encontraba "sobre un cerillo entre vestigios de edificios de su antigualla, que llaman cues, en los quales ordinariamente se hallan carbones y copal y otras señales de haber quemado semejantes sahumerios.” De León reveló que "otras faltas contra el divino culto, como es llevar a los cerros sangre de animales y gallos de la tierra a ofrecer." Cada mes de marzo, en un lugar situado a dos leguas del pueblo, se apilaba leña al pie de unas cruces que posteriormente eran quemadas. Los "indios diabólicos" de San Mateo, se afirmaba, "con sus malas costumbres y sobrada malicia tienen pervertido el pueblo de calidad y forma que sólo les ha quedado de cristianos el nombre." ${ }^{17}$ Fray Alonso al final tuvo que huir, echado de San Mateo por la villanía de los indígenas que creía estaban poseídos por el demonio y estaban conspirando para matarlo.

Por consiguiente, la vida en el "país real" chocaba dramáticamente con el proyecto legislado en el "país legal." Sin embargo, sería un error imaginar que, aunque los mayas del altiplano eran malos conversos, no se podía ganar nada explotándolos, que los españoles de alguna manera estaban dispuestos a abandonar fácilmente su búsqueda de poder y enriquecimiento. Los funcionarios tanto de la Iglesia como de la Corona se beneficiaban mucho a expensas de los indígenas, legalmente o de otra manera.

En términos de ilegalidad, una de las exigencias más odiosas llegaba en forma de repartimientos de mercancías. Bajo esta práctica, corregido-

17 AGI, AG 159, Obispo Andrés de las Navas y padres curas a la Corona, 1689. El expediente lleva el título Testimonio de los autos hechos sobre la perdición general de los indios de estas provincias y frangentes continuos que amenazan su libertad. 
res y alcaldes mayores, gobernadores que de hecho compraban los cargos públicos con la intención de enriquecerse, suministraban varios artículos a los indígenas, insistiendo en que fueran comprados a precios favorables para el vendedor, fuera o no deseada la mercancía por los recipientes. Una estrategia opuesta era obligar a la gente a que vendiera a precios bajísimos en un área, luego revender a precios más altos en otra. Los repartimientos aparecen en el siglo XVI, y también fueron una característica del XVII. Sin embargo, su apogeo fue en el siglo XVIII, especialmente en Chiapas, donde fueron impuestos con gran insistencia a las comunidades tzeltal y tzotzil, así como a la comunidad zoque (Cuadro 12). Un artículo popular en estas transacciones era el algodón, que los gobernadores distribuían en rama y al por mayor entre las mujeres indígenas, quienes eran obligadas a hilarlo y luego tejerlo en trozos de tela, o mantas. El artículo acabado producía buenas ganancias - para el corregidor o alcalde mayor, no para la trabajadora.

\section{CUADRO 12}

BENEFICIOS OBTENIDOS DE LOS REPARTIMIENTOS DE MERCANCÍAS

POR EL ALCALDE MAYOR DE CIUDAD REAL (SAN CRISTÓBAL DE LAS CASAS) EN CHIAPAS, 1760-65

Ganancias (en pesos)

Procesar 500.000 libras de algodón en rama

para convertirlo en 100.000 libras de hilo

Producción forzada de 100.000 libras de cochinilla

Producción forzada de 150.000 libras de cacao

Producción forzada de 12.000 manojos de tabaco

Ventas misceláneas forzadas

Fuente: Wasserstrom, Robert: Class and Society in Central Chiapas, Berkeley y Los Angeles: University of California Press, 1983, pág. 47.

Así como los indígenas eran vulnerables a la explotación de los funcionarios del gobierno, también así eran víctimas de las exacciones del clero. Una orden dictada ya en 1561 estipulaba qué artículos y servicios los curas podían pedir legítimamente a sus fieles. Sin embargo, los límites teóricos no siempre eran respetados, y aunque algunos individuos desintere- 
sados encontraban el llamado de Dios entre los mayas, otros se preocupaban más por el beneficio personal que por la salvación de los indígenas. Los documentos de archivo muestran que los abusos estuvieron nuevamente en su apogeo en el siglo XVIII, cuando se acusó a los curas y a los frailes de varios excesos, incluyendo no reembolsar por servicios personales, vender ganado sin el consentimiento del dueño, recaudación demasiado celosa de fondos para celebrar misa u oir confesión y malversación de fondos de las cofradías.

De hecho, fue $-\mathrm{O}$ así nos dice el cronista dominico Francisco Ximénez- el anuncio de que el obispo Juan Bautista Alvarez y Toledo tenía la intención de hacer una visita más, lo que provocó la sublevación más desconcertante de toda la época colonial, la de los tzeltales y tzotziles de 1712-13. En Chiapas, las visitas de Alvarez y Toledo eran legendarias, ya que pocas veces dejaban muchos recursos en las cajas de comunidad, fondos creados por los misioneros pero alimentados por los indígenas para reducir el impacto de todo tipo de calamidades. Habría que señalar que su inminente llegada se produjo a penas diez años después de que serios tumultos en otras partes de Chiapas, así como en partes vecinas de Guatemala, provocaran la investigación de actos de corrupción perpetrados por el visitador real, Francisco Gómez de Lamadriz. ${ }^{18}$ La inspección inesperada del obispo también debe ser vista en el contexto de las exigencias del tributo y las obligaciones del repartimiento de mercancías, por no mencionar el torbellino de religiosidad maya, una mezcla vertiginosa en la que muchos giros eran impredecibles. En relación con esto último, de la comunidad tzeltal de Cancuc era originaria una figura alrededor de la cual se organizaría en vano la protesta maya, una mujer joven que se llamaba María de la Candelaria o María de la Cruz, cuyos seguidores creían que se comunicaba con la Virgen María. Levántense, declaraba la visionaria tzeltal a sus desgraciados parientes, y acaben con la tiranía española, pues ese rey y su dios están muertos, y han sido remplazados por un rendentor maya que acabará con todos los infortunios:

Yo la Virgen que he bajado a este Mundo pecador os llamo en el nombre de nuestra Señora del Rosario y os mando que vengáis a este pueblo de Cancuc y os traigáis toda la plata de tus Iglesias y los ornamentos y campanas, con todas las Cajas [de comu-

18 León Cázares, María del Carmen: Un levantamiento en nombre del Rey Nuestro Señor: Testimonios indígenas relacionados con el visitador Francisco Gómez de Lamadriz, México: Universidad Nacional Autónoma de México, 1988. 
nidad] y los tambores y todos los libros y dineros de Cofradías porque ya no hay Dios ni Rey; y así venid todos cuanto antes, porque sino, seréis castigados pues no venis a mi llamado y a Dios. ${ }^{19}$

Después de los pronunciamientos de María, en los que la influencia del profeta tzotzil Sebastián Gómez de la Gloria debe también mencionarse, más de veinte pueblos se sublevaron, proporcionando ejércitos de 3.000 a 6.000 hombres. Sin embargo, la sublevación no pudo extenderse más allá de su centro tzeltal-tzotzil. La insurgencia maya al final se derrumbó ante una respuesta concertada del alarmado virrey de la ciudad de México; desde Tabasco y Guatemala se enviaron milicias bien equipadas a Chiapas. Las comunidades rebeldes, cuyos líderes fueron agarrotados o fusilados, sufrieron terriblemente durante años después. El viejo orden fue restaurado, incluso con más brutalidad que antes, pues los españoles no eran el tipo de gente que no comprendiera la importancia de dar una lección. El ejercicio de la autoridad ciertamente no pasó desapercibido para los mayas del altiplano, quienes a partir de entonces comprendieron mejor la fina línea entre resistencia y sublevación. Un siglo después, en Totonicapán, incluso cuando se enfrentaban a un régimen debilitado a punto de derrumbarse, los indígenas se cuidaban bien de que los disturbios por el pago de tributo no provocaran rebeliones totales..$^{20}$

A medida que se aproximaba la independencia, era evidente que poco había cambiado, o fuera a cambiar, en la forma fundamental en que los españoles de todas las clases trataban a - y se relacionaban con- los indígenas. Para ellos, como para los criollos y los ladinos, la subordinación maya no era una cuestión de polémica o debate: simplemente se daba por hecho, era algo que se consideraba un derecho natural, un elemento no cuestionado de la empresa imperial. La coexistencia bajo estos términos no fomentaba compasión ni respeto. Lo que sí engendraba eran sentimientos mutuos de sospecha, desconfianza, odio y miedo. "El régimen colonial," escribe el historiador guatemalteco Severo Martínez Peláez, "fue un régi-

19 De acuerdo con la versión de Francisco Ximénez: Historia de la provincia de San Vicente de Chiapa y Guatemala de la orden de predicadores, 3 vols., Guatemala: Sociedad de Geografía e Historia de Guatemala, 1929-31, III, pág. 271. Estudios críticos sobre la sublevación incluyen Gosner, Kevin: Soldiers of the Virgin: The Moral Economy of a Colonial Maya Rebellion, Tucson: University of Arizona Press, 1992, y Viqueira, Juan Pedro: Indios rebeldes y idólatras: Dos ensayos históricos sobre la rebelión india de Cancuc, Chiapas, México: Centro de Investigaciones y Estudios Superiores en Antropología Social, 1997.

20 Contreras, J. Daniel: Una rebelión indígena en el partido de Totonicapán: El indio y la Independencia, Guatemala: Imprenta Universitaria, 1951. 
men de terror para el indio.”. ${ }^{21}$ El antropólogo Michael Taussig está de acuerdo, y ofrece algunas observaciones perspicaces propias. El terror, afirma, no es solamente "un estado fisiológico," sino "un hecho social y una construcción cultural cuyas dimensiones barrocas le permiten servir de mediador, par excellence, de la hegemonía colonial." Como muchas características creadas por la conquista española, el espectro del terror -invadiendo los "espacios de la muerte" donde "los indígenas, los africanos y los europeos dieron vida al Nuevo Mundo"- atormentó la existencia maya hasta marcar y desfigurar los siglos siguientes. ${ }^{22}$

\section{Reforma y revolución}

La realidad compartida de ser maya une a las comunidades del altiplano en Chiapas y Guatemala después de la independencia, pero era inevitable que formar parte de dos agendas nacionales distintas al final resultaría en experiencias postcoloniales diversas. Sin embargo, durante gran parte del siglo XIX los mayas del altiplano lucharon contra problemas similares. Sólo en el siglo XX significó algo diferente ser maya del altiplano en México por contraste con maya del altiplano en Guatemala.

Después de que Agustín Iturbide llegó a un acuerdo de independencia en 1821 con el último virrey español, los criollos de Centroamérica que lo habían apoyado eligieron inicialmente identificarse con México. Este arreglo duró sólo dos años, ya que el imperialista Iturbide resultó insensible a las preocupaciones centroamericanas, fomentando así un movimiento separatista que condujo a la formación de las Provincias Unidas de Centroamérica, ella misma condenada a desmembrarse para formar las actuales repúblicas de Guatemala, Honduras, El Salvador, Nicaragua y Costa Rica. Chiapas permaneció en el redil mexicano, la única unidad que lo hizo de todo el territorio que (desde 1561) había sido gobernado como la Audiencia de Guatemala.

Tanto en Chiapas como en Guatemala, la batalla para derrocar a España fue seguida de un conflicto interno prolongado entre conservadores y liberales por el control de los puestos del gobierno. Las diferencias entre

21 Martínez Peláez, Severo: La patria del criollo: Ensayo de interpretación de la realidad colonial guatemalteca, México: Fondo de Cultura Económica, 1998, pág. 427.

22 Taussig, Michael: "Culture of Terror, Space of Death: Roger Casement's Putomayo Report and the Explanation of Torture," Comparative Studies in Society and History 26, 3, 1984: pág. 468. 
las dos facciones políticas eran muchas, pero giraban alrededor de las preferencias conservadoras por mantener instituciones que buscaban conservar el estatu quo colonial, en contraste con una preferencia liberal por crear un orden económico y social totalmente nuevo, promoviendo los vínculos capitalistas con el mundo exterior. En términos del impacto de la ideología en las costumbres mayas, el conservadurismo representaba más una continuación de la cultura de refugio formada durante la época colonial. El liberalismo, por otra parte, significaba la asimilación al estado ladino moderno que miraba hacia afuera. Las prácticas conservadoras a menudo provocaron cambio cultural mínimo al nivel de comunidad, mientras que las políticas liberales promovieron cambios que alterarían irrevocablemente formas de vivir con la tierra establecidas desde hacía mucho tiempo. Ninguna de las dos facciones pudo afirmar tener hegemonía incontestable hasta las décadas de 1860 y 1870 , cuando finalmente prevaleció la autoridad liberal.

En Chiapas, los conflictos políticos provocaron más de veinticinco transferencias de gobierno antes de 1850. Lo que permaneció constante fue el deterioro del bienestar indígena, especialmente la pérdida de tierra. A las comunidades mayas les confiscaron tierra que fue declarada "vacante," la cual fue a parar a manos de no indígenas emprendedores, quienes anunciaron su intención de dedicarla a "buen uso," especialmente los terrenos más templados que eran apropiados para los cultivos de exportación. Muchas comunidades mayas en Soconusco desparecieron completamente durante este proceso, mientras que las del altiplano también fueron severamente afectadas.

Jan Rus escribe que "de veinticinco municipios tzotziles y tzeltales intactos que existían al momento de la independencia, todos corrieron esta suerte en un grado u otro." Su investigación muestra que una familia ambiciosa, los larraínzars, tomaron posesión de tres cuartas partes de la tierra comunitaria de Chamula, 476 caballerías (unas 20.000 hectáreas) de un total de 636. Junto con otra tierra expropiada a otros dos municipios, los larraízars crearon Nuevo Edén, una enorme propiedad que medía unas 874 caballerías. En vez de abandonar físicamente la tierra que consideraban suya, los indígenas se quedaban como mano de obra contratada, trabajando en plantaciones de tabaco y caña de azúcar en elevaciones más bajas. Rus calcula que, a mediados de siglo, más de setecientas familias se encontraban en esta difícil situación, en la que los cabezas de familia proporcionaban tres días de trabajo cada mes para conservar el terreno que les servía 
para subsistir. Nuevo Edén, aunque ciertamente "una de las depredaciones más espectaculares de esta naturaleza," difícilmente era "única," ya que en un poco más de dos décadas, "más de la cuarta parte de los indígenas de Chiapas" se vieron transformados de "aldeanos libres en peones y trabajadores permanentes y legalmente obligados." ${ }^{123}$ Las usurpaciones ladinas se aceleraron bajo las leyes reformistas aprobadas por el presidente liberal Benito Juárez, quien puso en vigor las mismas en 1863. George Collier nos informa que en ese entonces los ladinos adquirieron "varios terrenos que antes eran comunales" en Zinacantán, donde, entre 1838 y 1875, Robert Wasserstrom calcula que "aproximadamente la mitad de los residentes del pueblo se volvieron arrendatarios." ${ }^{24}$ En vísperas de la Revolución mexicana, después de las iniciativas de modernización del dictador liberal Porfirio Díaz (1876-1910), más de diez millones de pesos de capital extranjero habían sido invertidos en Chiapas, gran parte de éste en la producción de café en Soconusco y en operaciones madereras en el extremo oriente del estado, en la Selva Lacandona. A los mayas del altiplano, obligados a trabajar bajo contrato, les tocaba cosechar el café y cortar los bosques de caoba y cedro.

En Guatemala, los liberales dominaron la vida política entre 1823 y 1839 , pero sus planes para una reforma radical fueron paralizados, si no anulados durante un período de tres décadas, cuando Rafael Carrera llevó a los conservadores al poder después de una sublevación popular. Individuo astuto que llegó a ser conocido como el "protector del pueblo," Carrera deshizo el trabajo de su predecesor liberal, Mariano Gálvez, y creó un estado paternalista fundado en instituciones españolas restauradas. No está claro hasta dónde los indígenas de Guatemala se beneficiaron de la agenda política de Carrera. Aunque Lee Woodward mantiene que "la política proindígena de Carrera de hecho protegió a los indígenas de más usurpaciones de su tierra y trabajo durante la década de 1840," concede que "después de

23 Rus, Jan: "Whose Caste War? Indians, Ladinos, and the Chiapas 'Caste War' of 1869,” en MacLeod, Murdo J., y Wasserstrom, Robert (editores): Spaniards and Indians in Southeastern Mesoamerica, Lincoln and London: University of Nebraska Press, 1983, págs.132-33. El análisis de Rus está disponible en castellano: “¿Guerra de castas según quién? Indios y ladinos en los sucesos de 1869", en Viqueira, Juan Pedro y Ruz, Mario Humberto (editores): Chiapas: Los rumbos de otra historia, México: Universidad Nacional Autónoma de México, 1998, págs. 146-174.

24 Collier, George A.: Fields of the Tzotzil: The Ecological Bases of Tradition in Highland Chiapas, Austin: University of Texas Press, 1975, pág. 144 y Robert Wasserstrom: Class and Society in Central Chiapas, Berkeley, Los Angeles: University of California Press, 1983, págs. 134-35. El estudio de Wasserstrom está disponible en castellano bajo el título Clase y sociedad en el centro de Chiapas, México: Fondo de Cultura Económica, 1989. 
1850, esa protección empezó a disminuir, cuando Carrera empezó a ligarse más claramente con la élite." ${ }^{25}$ Cualquier interpretación que se favorezca, en comparación con lo que les estaba sucediendo a los mayas del altiplano de Chiapas, los mayas de Guatemala encontraron en Carrera un escudo útil aunque temporal.

Los liberales volvieron a conseguir el poder político en 1871, seis años después de la muerte de Carrera, y bajo la administración de Justo Rufino Barrios empezaron a implementar con fervor lo que no habían podido hacer durante las cuatro décadas anteriores. Los ataques a la tierra y los asaltos a la mano de obra eran consecuencias inevitables de la visión liberal. La legislación exigía que la tierra fuera declarada formalmente y, si era posible, que fuera registrada no con título colectivo sino con título individual. Sin embargo, las proclamaciones del gobierno no siempre llegaban a oídos indígenas, ni tampoco eran entendidas cuando llegaban. Como en Chiapas, tierras consideradas "no reclamadas" por la administración liberal cayeron en manos de criollos y ladinos mucho más versados que los campesinos indígenas en los detalles de la legislación reformista. Los estudios de esta usurpación sin precedentes son escasos. Dada la sensibilidad política de la cuestión, la magnitud de la apropiación y el impacto que produjo, quizás nunca se puedan determinar con exactitud. Robert Naylor mantiene de que hubo "poco cambio discernible" en la vida maya, de que continuó "casi igual que antes." Más realista es la evaluación de Carol Smith, que los indígenas "perdieron casi la mitad de las tierras que tradicionalmente reclamaban como suyas durante el período colonial.".26

La adquisición de tierra fue impulsada por el hecho de haberse dado cuenta de que varias regiones de Guatemala, especialmente Verapaz y la Boca Costa del Pacífico, ofrecían condiciones agrícolas ideales para el cultivo del café. Siendo zonas que no habían sido tocadas relativamente por el auge del cacao y la fiebre del índigo durante la época colonial, Verapaz y la Boca Costa se convirtieron en centros de especulación agraria considerable. La inversión de capital nacional y extranjero hizo que el café se convirtiera en el principal cultivo de exportación de Guatemala durante la

25 Woodward, Ralph Lee, Jr.: "Changes in the Nineteenth-Century Guatemalan State and Its Indian Policies," en Smith, Carol A.: editor, Guatemalan Indians and the State, 1540-1988, Austin: University of Texas Press, 1990, pág. 68.

26 Naylor, Robert A.: "Guatemala: Indian Attitudes Toward Land Tenure," Journal of InterAmerican Studies 9, 4, Gainsville, Florida, 1967, pág. 629, y Carol A. Smith, "Local History in Global Context: Social and Economic Transitions in Western Guatemala," Comparative Studies in Society and History 26, 2 (1984): pág. 204. 
segunda mitad del siglo XIX, posición que ha mantenido en la economía nacional desde los tiempos de Barrios hasta el presente.

Cuando está organizada como plantación o finca, como en su mayoría lo está en Guatemala, la producción de café exige inversiones intensivas de mano de obra sólo en la época de cosecha. Por lo tanto, lo que más conviene a las necesidades de los cafetaleros es una fuerza de trabajo estacional, una que proporciona mano de obra cuando se necesita y de la que se puede prescindir cuando no. Como en Chiapas, desde hace más de un siglo, los mayas migrantes han cumplido con este requisito.

Los métodos adoptados para conseguir mano de obra han variado a través de los años. La pura coerción en forma de mandamientos, autorizados por el presidente Barrios en noviembre de 1876, reforzó la práctica existente durante muchos años del trabajo por deudas legalizado, el cual perduró en Guatemala hasta ya bien entrado el siglo XX, cuando al final fue reemplazado por una ley de vagancia que exigía que los invididuos que poseían menos de una cantidad estipulada de tierra trabajaran parte del año como trabajadores asalariados para otros: cualquiera que cultivara diez o más cuerdas, pero menos de tres o cuatro manzanas que le daban derecho a una exención, se esperaba que trabajara cien días; cualquiera que cultivara menos de diez cuerdas se esperaba que trabajara ciento cincuenta días. ${ }^{27}$ Un hombre debía llevar consigo una libreta de identificación en todo momento, y lo ideal era que al ser inspeccionada se hubiese cumplido con el número requerido de días. Los efectos de estas exigencias, según David McCreery, era "agravar la diferenciación social dentro de las comunidades y contribuir a la destrucción de las estructuras autoprotectores corporativas." McCreery también afirma que tales exigencias "aseguraban la rentabilidad de la principal exportación, empobrecían a la población rural y contribuían a las precondiciones de la actual violencia." ${ }^{28}$

Dos investigaciones proporcionan detalles locales que respaldan la afirmación de McCreery, uno de Shelton Davis relacionado con lo que ocurrió en Santa Eulalia, otro de Robert Carmack relacionado con acontecimientos en Momostenango. Davis calcula que, entre 1880 y 1920, aproximadamente 70 por ciento de las propiedades comunales de Santa Eulalia cayeron en manos de ladinos, incluyendo terrenos muy valiosos en la tierra

27 Una cuerda es una unidad agraria variable, la cual mide 0.11 acres o 0.27 acres. Una manzana es aproximadamente igual a 1.7 acres.

28 McCreery, David J.: "Debt Servitude in Rural Guatemala, 1876-1936," Hispanic American Historical Review 63, 4 (1983): págs. 758-59. 
caliente de la región de Ixcán, "zonas de gran potencial ecológico y económico." De cincuenta y cinco terrenos titulados en estas partes, los indígenas recibieron sólo nueve; de las 1.520 caballerías involucradas en el proceso de titulación, a los indígenas les fueron otorgadas $183 .{ }^{29}$ Los ladinos titularon la tierra, como deseaba el gobierno, individualmente, no como cuerpo corporativo, la forma maya para reivindicar la tierra. Mientras que los ladinos se dividían las áreas de la tierra caliente, los indígenas se concentraron en adquirir título legal de la tierra fría, en la vecindad del centro del pueblo. El resultado fue el surgimiento de una dicotomía clásica de grandes propiedades poseíadas por los ladinos en las tierras bajas y un mosaico de campos pequeños cultivados por los indígenas en las tierras altas.

Davis registra que la primera tierra que se perdió quedaba cerca de Santa Cruz Yalmux, donde un grupo de ladinos de Huehuetenango reivindicaron unas 200 caballerías. Los demandantes, miembros de la milicia local, presentaron su caso el 22 de mayo de 1888, apareciendo en persona ante el general Manuel Lisandro Barillas, entonces presidente de Guatemala. Reclamaron derechos de propiedad por razones de que: (1) las propiedades de Santa Eulalia en tierra fría "eran grandes y suficientes" para los indígenas que vivían allí; (2) los solicitantes usarían las tierras que querían titular "para el desarrollo de la agricultura capitalista"; (3) durante "la llegada al poder del Justo Rufino Barrios," Huehuetenango jugó un "papel militar" que el gobierno estaba obligado a reconocer; y (4) otorgar título de la tierra permitiría la creación de un nuevo municipio, el cual funcionaría "como puesto militar avanzado para la protección de la frontera entre México y Guatemala," a lo largo del río Usumacinta. A pesar de las protestas de que los demandantes "sólo querían obtener títulos de esta tierra para revenderla después a los residentes indígenas," el gobierno de Barillas en julio de 1888 otorgó 200 caballerías de tierra en Yalmux a los ladinos de Huehuetenango. El 17 de octubre de ese mismo año, se formó el municipio de Barillas. La elección de topónimo relacionó directamente la acción del gobierno con la erosión de las tierras mayas. ${ }^{30}$

Los indígenas de Momostonango, nos informa Carmack, "perdieron sus mejores tierras agrícolas bajo el gobierno liberal — cuarenta y seis caballerías de tierras llanas y fértiles en Buenabaj- y varios cientos de

29 Una caballería de tierra mide unos 112 acres o 45.4 hectáreas.

30 Davis, Shelton H.: La tierra de nuestros antepasados: Estudio de la herencia y la tenencia de la tierra en el altiplano de Guatemala, Antigua Guatemala: Centro de Investigaciones Regionales de Mesoamérica y South Woodstock, VT: Plumsock Mesoamerican Studies, 1997, págs. 40-44. 
caballerías de tierras de boca costa en El Palmar y Samalá." Aunque la cantidad de tierra perdida en términos absolutos era menor que en Santa Eulalia, la incautación de propiedad nativa era tal que, como la población se duplicó de tamaño durante el siglo XIX, la propiedad familiar promedio disminuyó a menos de media hectárea, lo cual significa que "la escasez de tierra alcanzó proporciones de crisis." Carmack considera que las reformas liberales fueron "desastrosas" y "censurables" hasta el punto de que, en 1876, produjeron una "insurección total," que el régimen de Barrios reprimió brutalmente. Adoptando estrategias usadas por las fuerzas armadas guatemaltecas un siglo después, Barrios ordenó que su milicia "quemara las casas y las cosechas en las zonas rebeldes de Momostenango" y que reasentara forzosamente en el pueblo a "muchas familias que se sospechaba estaban ayudando a los rebeldes."

Las tropas gubernamentales no tardaron en salir victoriosas, capturando y encarcelando a los rebeldes, muchos de los cuales fueron ejecutados. Carmack concluye que "los últimos cincuenta años de gobierno liberal en Momostenango fueron una época de intensa represión política y económica para los indígenas." Durante este período ladinos locales establecieron "vínculos personales íntimos con los dictadores nacionales." Los ladinos aprovecharon estos vínculos "para establecer un sistema autoritario de gobierno dentro de la comunidad." De 1.000 a 2.000 momostecos, calcula Carmack, fueron canalizados cada año a la región cafetalera de la boca costa, además de ser obligados a prestar servicio público dentro del pueblo mismo. De esta manera, los indígenas contribuían más de 336.000 días por año (16 por ciento del total disponible) en trabajo forzado. Los mismos eran vigilados en sus esfuerzos por ladinos que gobernaban por medio de "una elaborada mezcla de terror y paternalismo." En otra estrategia a la que recurrieron opresores posteriores, los hombres indígenas, para probar su lealtad a un "estado prácticamente facista," eran obligados a participar "en un sistema de milicia y servicio activo casi constantes," lo cual significaba que la "seguridad" de la comunidad tenía prioridad sobre los asuntos personales o familiares. ${ }^{31}$

Desde la época de Barrios y sus sucesores, han ocurrido cambios importantes en la manera en que se reclutan mano de obra indígena para las fincas. Sin embargo, la necesidad de forzar a los trabajadores ha disminuido a través de los años, ya que el crecimiento demográfico explosivo en

31 Carmack, Robert M.: "Spanish-Indian Relations in Highland Guatemala, 1800-1944," en MacLeod, Murdo J., and Wasserstrom, Robert (editores): Spaniards and Indians..., págs. 242-244. 
Guatemala, y la necesidad de ganar más dinero para dar de comer a más bocas, normalmente aseguran una fuerza de trabajo abundante. Esto ha sido así especialmente entre los minifundistas indígenas, aproximadamente 90 por ciento de los cuales viven con sus familias en terrenos demasiado pequeños para proporcionar empleo y subsistencia durante todo el año. Si la coacción disfrazada de cuadrillas de trabajo o leyes de vagancia ha desaparecido, no ha sido así con la desigualdad estructural ni la manipulación étnica que impulsan la migración estacional. En Guatemala, apenas 3 por ciento del número total de propiedades agrícolas ocupan 63 por ciento del área agrícola total, mientras que 90 por ciento del número total de propiedades agrícolas dan cuenta de 16 por ciento del área agrícola total. La mejor tierra continúa siendo usada para cultivar café, junto con algodón, bananos y caña de azúcar, para la exportación, no para alimentar a las poblaciones locales desnutridas, 70 por ciento de las cuales viven en una estado de pobreza que los estadísticos de la ONU describen como "extrema." ${ }_{32}$

El único intento serio para enfrentar, si no para enmendar, éstas y otras injusticias ocurrió durante un período "revolucionario" de diez años (1944-54), del cual, como nación moderna, Guatemala no se ha recuperado. Cómo los intereses extranjeros y la oposición nacional unieron fuerzas para poner obstáculos y luego derrocar al gobierno de Jacobo Arbenz Guzmán es suficientemente conocido como para justificar que no sea repetido aquí. Si uno acepta el razonamiento de Robert Wasserstrom por encima del de Jim Handy y Piero Gleijeses, entonces Arbenz "buscaba mitigación, no metamorfosis," y las reformas que implementó constituían en esencia "un programa modesto, no un programa audaz." De acuerdo a como lo ve Wasserstrom, Arbenz operaba creyendo erróneamente que "las dificultades internas de Guatemala se derivaban principalmente de la ignorancia y el aislamiento de su población indígena." Lo que Arbenz y sus seguidores no entendieron fue que "la agricultura comercial de Guatemala representaba una forma especial de capitalismo que había promovido la propagación de la agricultura de subsistencia y la tenencia de la tierra en forma de minifundios." Creyendo que los "viejos antagonismos entre indígenas y ladinos desparecerían cuando, con el tiempo, los siervos indígenas fueran integrados en la vida nacional," la plataforma de Arbenz desafió a, y fue derrotada por, una variante más poderosa e insidiosa del capitalismo

32 Para una amplia discusión del tema, véase Castellanos Cambranes, Julio (editor): 500 años de lucha por la tierra: Estudios sobre propriedad rural y reforma agraria en Guatemala, 2 tomos, Guatemala: Facultad Latinoamericana de Ciencias Sociales, 1992. 
que, desde entonces, se ha adaptado a las peculiaridades étnicas y geográficas de Guatemala. Lo que Arbenz nunca comprendió, argumenta Wasserstrom, fue que el capitalismo había evolucionado simbióticamente en Guatemala para crear una situación en la que las comunidades mayas y las fincas de la boca costa existían en grados variables de interdependencia, unas con otras. En este entorno específico, la lógica capitalista dictaba que "si las primeras perduran, las últimas tienen asegurada la mano de obra que necesitan." 33

Cualesquiera que hayan sido los beneficios que los indígenas obtuvieron bajo el gobierno de Arbenz, estos fueron efímeros. Después de la Revolución mexicana, se puede decir que a los mayas del altiplano de Chiapas les fue un poco mejor, ya que a pesar de la persistencia de manifiestas desigualdades y serias lagunas en la legislación de la tenencia de la tierra, a las comunidades indígenas de allí por lo menos les escucharon algunas de sus quejas, aunque de ninguna manera se las resolvieron completa.

Durante los primeros quince años después de que la guerra civil en México hubiese terminado, la economía cafetalera de Chiapas continuó creciendo, siendo la mano de obra indígena (como en Guatemala) una de las piedras angulares de la prosperidad. La reforma llegó primero en relación con las condiciones de empleo, específicamente el establecimiento de la Oficina de Contrataciones y el Sindicato de Trabajadores Indígenas, a finales de la década de 1930. Estas agencias requerían, respectivamente, que los indígenas que trabajaban en las fincas negociaran un contrato y se afiliaran a un sindicato, proporcionándoles así, en teoría, garantías gubernamentales de que (1) recibirían el salario mínimo legal y (2) que serían tratados de acuerdo con los códigos laborales defendidos por la administración de Lázaro Cárdenas (1934-1940) en la Ciudad de México. Gran parte del mérito de organizar a los trabajadores indígenas pertenece a Erasto Urbina, personaje popular que se moldeó al estilo de su mentor presidencial. El éxito de Urbina en el frente laboral le dio la seguridad, después de que Cárdenas lo nombrara director del Departamento de Protección Indígena, para organizar la restitución de la tierra, la cual suponía devolver

33 Wasserstrom, Robert: "Revolution in Guatemala: Peasants and Politics under the Arbenz Government," Comparative Studies in Society and History 17, 4, London, 1975, pág. 478. Para otras interpretaciónes, véase Handy, Jim: Revolution in the Countryside: Rural Conflict and Agrarian Reform in Guatemala, 1944-1954, Chapel Hill: University of North Carolina Press, 1994, y Gleijeses, Piero: Shattered Hope: The United States and the Guatemalan Revolution, Princeton: Princeton University Press, 1991. 
a las comunidades nativas, en forma de ejidos, muchas de las propiedades que les habían quitado durante el siglo XIX.

Aunque el historial de Urbina es impresionante, Wasserstrom nuevamente aconseja la cautela, ya que a los dueños de grandes propiedades en Chiapas "por lo general se les permitió conservar sus mejores tierras y parcelas irrigadas." Wasserstrom calcula que "de las 62.000 familias que se habían beneficiado con la reforma agraria, por lo menos un tercio poseían recursos insuficientes para sostenerse.” Además, su valoración de la reforma agraria en Zinacantán indica que "casi la mitad de las familias que tenían derecho a recibir parcelas" fueron excluidas del proceso, cuando la mayoría de los hacendados conservaron "tanto sus mejores campos como el control de los suministros de agua." En consecuencia, "60 por ciento de la concesión final del pueblo estaba compuesta de bosques y laderas, mientras que sólo 40 por ciento contenía tierras de labrantío estacionales." ${ }^{34}$ Deficiencias como éstas, junto con la ausencia casi total de iniciativas gubernamentales en áreas remotas y desheredadas del oriente de Chiapas, templaron el impacto de la reforma. Sin embargo, como expresa sucintamente Collier, la legislación que gobernaba la tierra y la tenencia de la tierra, en el altiplano central en todo caso, "transformaron las comunidades indígenas de un mosaico de chozas pequeñas, diseminadas entre las propiedades ladinas, en un área de control indígena consolidado y continuo." ${ }_{35}$ Ninguna reparación similar a ésta ha sido alguna vez soñada por cualquier gobierno de Guatemala.

\section{Marginalización y descuido}

La segunda mitad del siglo XX marca la bifurcación del destino de los mayas del altiplano en dos trayectorias más definidas, si bien décadas de marginalización y descuido aseguran que la pobreza prevalezca como suerte común de los indígenas, tanto en Chiapas como en Guatemala. Políticamente, Chiapas es tal vez el más complejo de los dos casos al que hay que enfrentarse. Aunque los indígenas de allí han tenido que afrontar toda clase de descriminación, como atestiguan irrefutablemente las novelas de Rosarios Castellanos y B. Traven, incluso un observador tan cauteloso

34 Wasserstrom, R.: Class and Society..., págs. 167 y 171.

35 Collier, G.: Fields of the Tzotzil..., pág. 150. 
como Wasserstrom admite que, en 1950, "la reforma agraria y medidas similares habían alterado profundamente todo el tejido de las relaciones sociales en el área central de Chiapas.. ${ }^{{ }^{36}}$ ¿Qué fue, por consiguiente, lo que ejerció una presión tan tremenda en el tejido social y finalmente hizo que se rasgara, provocando la sublevación zapatista del $1^{\circ}$ de enero de 1994 ?

Como en el caso de Guatemala, se puede mencionar primero el ritmo acelerado de crecimiento de población desde 1950 en adelante. Retrospectivamente, la historia de la población de Chiapas y Guatemala (véanse Cuadros 1-6) puede ser interpretada como una en que, después de un colapso demográfico después de la conquista, hicieron falta más de cuatro siglos para que los pueblos mayas recuperaran las cantidades que sumamaban al momento del contacto, sólo para que ocurriera la duplicación de tamaño en el espacio de una generación. Tal crecimiento reciente sin precedentes pondría a prueba la resolución política y colocaría una carga material en los recursos de la mayoría de los países, pero en dos naciones tan divididas como México y Guatemala, donde la distancia entre unos pocos ricos y muchísimos pobres adquiere una dimensión étnica y de clase, las implicaciones para la estabilidad social han sido profundas.

Durante décadas, el gobierno mexicano mantuvo la paz en el área rural adhiriéndose a la retórica, aunque no siempre a la realidad, de la reforma agraria, consagrada en el Artículo 27 de la constitución mexicana. Extendiendo por lo menos la promesa de reforma agraria a las comunidades rurales empobrecidas, así como proporcionando acceso a crédito y subvencionando provisiones básicas tales como el maíz y la leche, el Partido Revolucionario Institucional (PRI) pudo contar con apoyo campesino amplio, elección tras elección. Chiapas ha sido un partidario leal del PRI, votando 89.9 por ciento a favor del candidato del PRI, Carlos Salinas de Gortari, en las elecciones presidenciales de 1988. El predecesor de Salinas, Miguel de la Madrid (1982-88), había precidido un programa de austeridad diseñado por la comunidad bancaria internacional para reducir la inmensa deuda extranjera de México, la cual el país había acumulado durante el efímero pero desastroso auge petrolero entre 1972 y 1982. Salinas estaba dispuesto a exprimir aun más a la base campesina del PRI, para satisfacer las presiones externas que exigían un "ajuste estructural" de la economía mexicana que introduciría al país en una nueva era marcada por la asociación de México con los Estados Unidos y Canadá en el Tratado de Libre

36 Wasserstrom, R.: Class and Society..., pág. 214, 251. 
Comercio Norteamericano. Asociada con una visión de modernización similar a la del dictador liberal Porfirio Díaz hace un siglo, en la que la tierra, el trabajo y los recursos naturales se abrirían a la inversión extranjera, en un esfuerzo para estimular el desarrollo económico, la política del Tratado de Libre Comercio significó mayores apuros para la gente en Chiapas, especialmente en partes de la frontera oriental del estado, donde las condiciones de vida son especialmente difíciles.

Las cosas se movieron hacia el punto de ruptura en 1992, cuando el gobierno de Salinas, en un cambio dramático de la raison d'être del PRI, redactó de nuevo el Artículo 27 de la constitución mexicana, acabando así con un compromiso con la reforma agraria que de hecho había definido la relación del estado con sus electores campesinos durante medio siglo. "En Chiapas," insisten George Collier y Elizabeth Lowery Quaratiello, "donde muchas reclamaciones de tierra aún no han sido resueltas después de languidecer en la burocracia estatal durante años, la anulación de la legislación de la reforma agraria les quitó a muchos campesinos no sólo la posibilidad de obtener un pedazo de tierra, sino simplemente la esperanza." La sublevación zapatista, que Collier y Quaratiello creen es "principalmente una rebelión campesina, no una rebelión exclusivamente indígena," tal vez se entiende mejor como una protesta popular contra la violación gubernamental de un contrato social de muchos años. ${ }^{37}$ Aunque comenzó en Chiapas, y sin lugar a dudas incluye a los pueblos mayas y responde a una serie de derechos y cuestiones mayas, el desafío zapatista transciende las fronteras locales y regionales y reverbera con significación simbólica en todo México, forzando una reevaluación de la política, la economía, la ideología y la identidad de la nación.

En Guatemala, la política de la Guerra Fría que tuvo mucho que ver con el derrocamiento del gobierno de Arbenz en 1954 ha estado tan arraigada y ha sido tan penetrante como la actitud del PRI en México. Seis años después de la caída de Arbenz, oficiales jóvenes de las fuerzas armadas nacionales organizaron un golpe frustrado contra el gobierno del general Ydígoras Fuentes, cuyas secuelas señalaron el comienzo de una brutal guerra civil que se prolongó, intermitentemente, durante treinta y seis años. En

37 Collier, George A., y Lowery Quaratiello, Elizabeth: Basta! Land and the Zapatista Rebellion in Chiapas, Oakland, California: Institute for Food and Development Policy, 1994, págs. 7 y 45. Para otras perspectivas, véase Neil Harvey, The Chiapas Rebellion: The Struggle for Land and Democracy, Durham: Duke University Press, 1998, y Womack, John (editor): Rebellion in Chiapas, New Press: New York, 1999. 
la década de 1960, la guerra ocurrió principalmente en el oriente, la región de Guatemala donde los ladinos superan en número a los habitantes indígenas, pero cuando los insurgentes trasladaron el foco de sus actividades más hacia el occidente y el norte, en la década de 1970, quedó preparado el escenario para una confrontación sangrienta en el altiplano maya.

El frente presentado por una serie de gobiernos militares al mundo exterior era que sus tropas estaban participando en una guerra de contrainsurgencia para liberar a Guatemala de la "subversión comunista." Entre 1978 y 1983, la violencia segó la vida de más de 200.000 de indígenas mayas, la mayoría de ellos no combatientes, incluyendo muchas mujeres y muchos niños. Los gobiernos militares dirigidos por tres generales, Romeo Lucas García (1978-1982), Efraín Ríos Montt (1982-1983) y Oscar Mejía Víctores (1983-1986), son los principales responsables por las atrocidades. Sin embargo, los insurgentes de ninguna manera están libres de culpa. Especialmente en Huehuetenango y El Quiché, los indígenas sufrieron terriblemente cuando el Ejército Guerrillero de los Pobres se batió en retirada ante las continuas ofensivas gubernamentales, dejando atrás a aldeanos desarmados que tuvieron que soportar represalias horrendas por haber proporcionado comida, refugio o apoyo moral a los rebeldes. Atrapadas en el fuego cruzado, cientos de comunidades mayas pagaron con creces por su proximidad a la insurrección, ya sea directa o indirecta, real o imaginada. ${ }^{38}$

Cualquier base rural popular de la que disfrutaron los insurgentes fue erosionada, poco a poco, no sólo por masacres viles sino también por bombardeos aéreos, la destrucción de propiedad y pertenencias personales, la quema de cosechas y provisiones, la matanza de ganado y la reagrupación de comunidades sospechosas en "aldeas modelos" y "polos de desarrollo," supervisados por tropas gubernamentales y patrullas de defensa civil organizadas por el ejército. ${ }^{39}$ La magnitud de cualquier reparación futura, en el altiplano maya sobre todo, será inmensa.

En 1986, un gobierno civil dirigido por Vinicio Cerezo Arévalo asumió el poder en Guatemala. Cerezo fue sucedido, cinco años más tarde, por otro presidente civil, Jorge Serrano Elías. Serrano abolió las garantías cons-

38 Hay dos informes voluminosos sobre la guerra civil, uno de la Oficina de Derechos Humanos del Arzobispado, Guatemala: Nunca Más, 1998, y otro de la Comisión de Esclarecimiento Histórico, Guatemala: Memoria del Silencio, 1999.

39 Véase Schirmer, Jennifer: The Guatemalan Military Project: A Violence Called Democracy, Philadelphia: University of Pennsylvania Press, 1999, y Rosada-Granados, Héctor: Soldados en el poder: Proyecto militar en Guatemala, 1944-1990, Amsterdam: Thela Latin American Series, 1999. 
titucionales el 25 de mayo de 1993, intentando gobernar por decreto, medida que provocó resistencia popular y al final condujo a su destitución. Ramiro de León Carpio asumió la presidencia el 6 de junio de 1993. Él, a su vez, entregó el cargo en enero de 1996 a Alvaro Arzú, cuyo gobierno firmó un acuerdo de paz "firme y duradera" con los insurgentes el 29 de diciembre de 1996.

Sin embargo, la reforma agraria no figuró en los términos del acuerdo de paz, ni en la agenda presidencial de Arzú (1996-2000) o en la de su sucesor, Alfonso Portillo. Es difícil imaginar cómo una paz "firme y duradera" puede alcanzarse sin una reevaluación fundamental de la forma en que la tierra es poseída y trabajada. Guatemala no es un país pobre. Es rica en recursos, naturales y humanos. Guatemala ha sido convertida en un país pobre porque el acceso a sus recursos, especialmente sus recursos agrarios, está caracterizado por estructuras paralizantes de desigualdad. Hasta que no se haga frente a la cuestión de la tierra, y a la dignidad de los pueblos mayas con ella, la causa principal de la agitación civil seguirá sin ser atendida. ${ }^{40}$

Mientras tanto, como lo hicieron sus antepasados siglos antes, los mayas del altiplano continúan adaptándose y sobreviviendo, respondiendo a la adversidad o a la falta de oportunidad en formas que nos obligan, una y otra vez, a reevaluar nuestras representaciones. Por ejemplo, ya no podemos considerar que los refugios montañosos de Chiapas y Guatemala son su dominio espacial exclusivo o predominante, ya que los mayas del altiplano ahora viven y trabajan lejos de sus lugares de origen en Mesoamérica. Son especialmente numerosos en el sur de los Estados Unidos, en California, Texas y Florida, tres de los muchos estados a donde huyeron los mayas de Guatemala durante los años violentos de la década de 1980. Sin embargo, también se pueden encontrar concentraciones mayas mucho más al norte, en las ciudades de Chicago, Boston y Providence, Rhode Island, incluso en partes de Canadá. Las descripciones estáticas que los representan como "hombres de maíz," para invocar el término del escritor guatemalteco Miguel Angel Asturias, deben ser reconciliadas con una red de improvisaciones en curso, ya que la supervivencia depende, como siempre, en hacer lo que haga falta para ganarse la vida, incluyendo vivir y trabajar en un entorno urbano norteamericano desconocido, a miles de kilómetros de sus milpas milenarios.

40 Lovell, W. George: A Beauty That Hurts: Life and Death in Guatemala, Austin: University of Texas Press, 2000, págs. 153-192. 
Aunque la diáspora maya comenzó como respuesta a la violencia y la represión, desde entonces a los refugiados políticos se ha unido una avalancha de personas que buscan mejoría económica y social. Se cree que hasta un millón de guatemaltecos residen actualmente, algunos legalmente, la mayoría no, en Estados Unidos y Canadá, un número considerable de ellos mayas. Aproximadamente 500 millones de dólares se envían o se llevan a Guatemala cada año en forma de remesas familiares, cuyo impacto, a nivel de comunidades individuales, puede ser considerable. Por ejemplo, el 13 de noviembre de 1996 el periódico guatemalteco Prensa Libre informó que en 1995 sólo la comunidad de Santa Eulalia recibió \$3 millones en remesas familiares, enviadas por más de 6.000 mayas q'anjoba'les que viven y trabajan en los Estados Unidos, la mayoría de ellos en California. Hacer frente a las redes migratorias en una esfera transnacional que abarca los Estados Unidos y Canadá, así como México y Guatemala, es actualmente una realidad de la vida maya del altiplano como lo era enfrentarse a las demandas de la encomienda y el mandamiento en épocas pasadas. Sin importar cuál sea el desafío, los mayas del altiplano están equipados culturalmente para perdurar. 


\section{Mapas}

MAPA 1

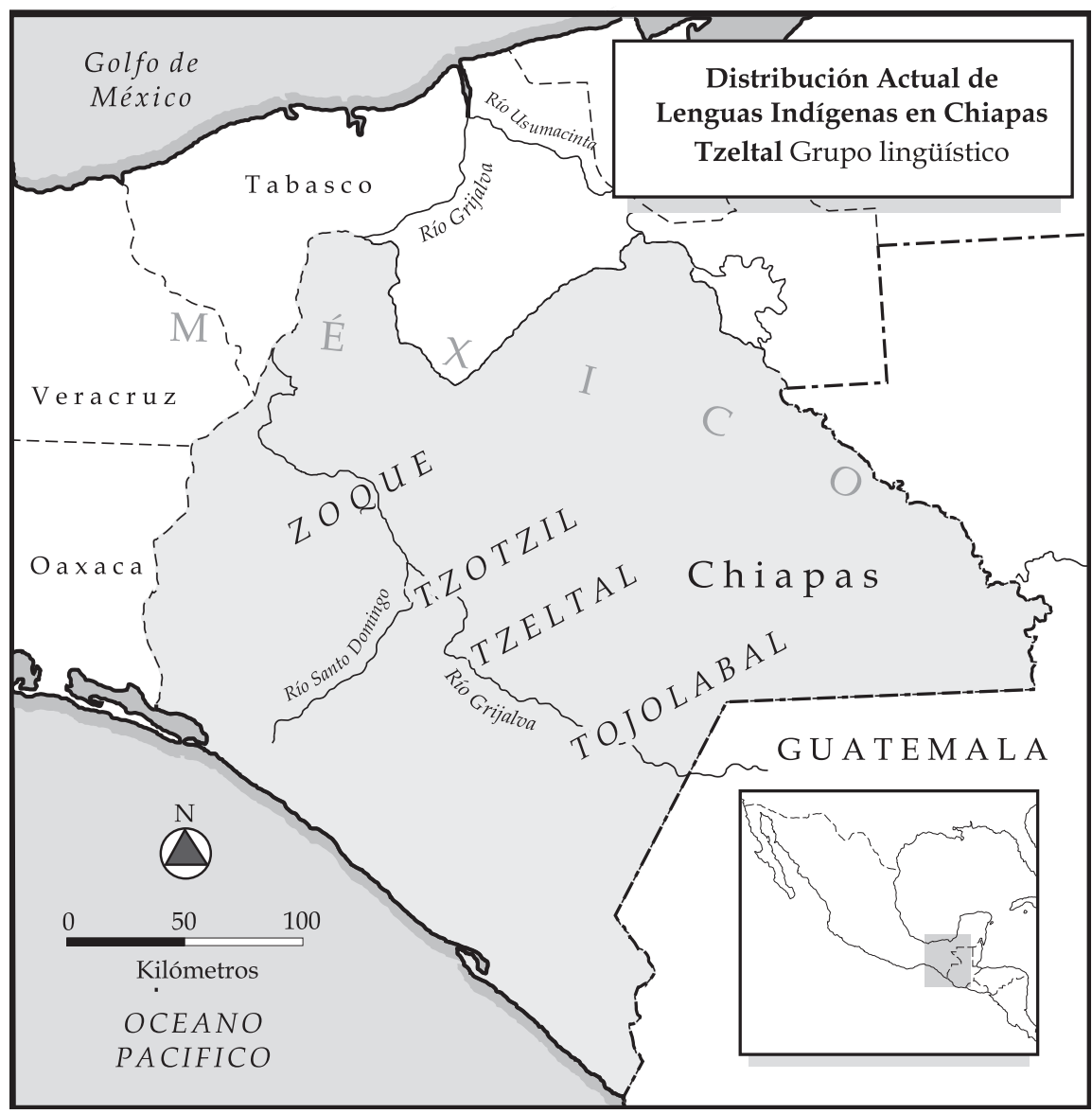


W. GEORGE LOVELL

MAPA 2

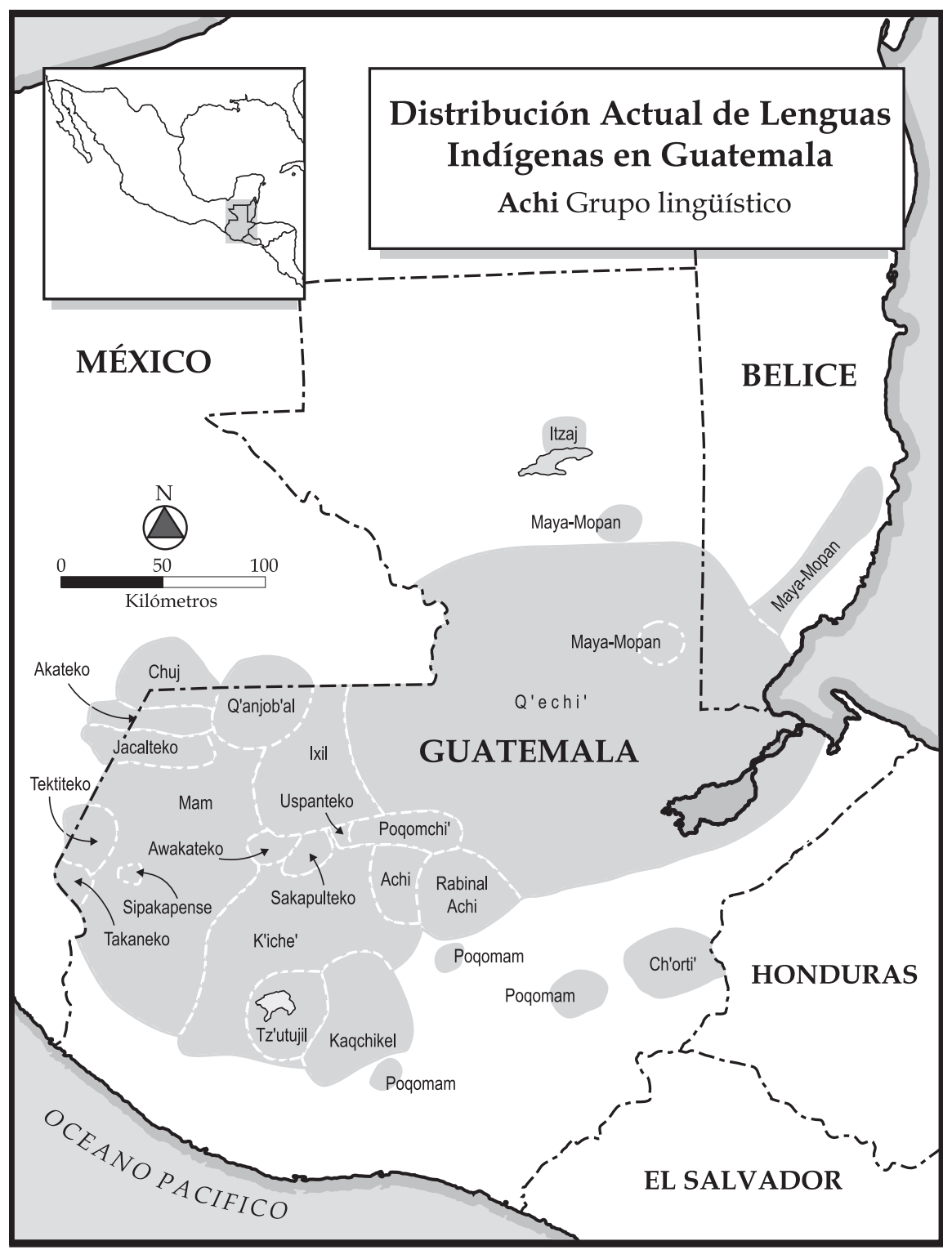


MAPA 3

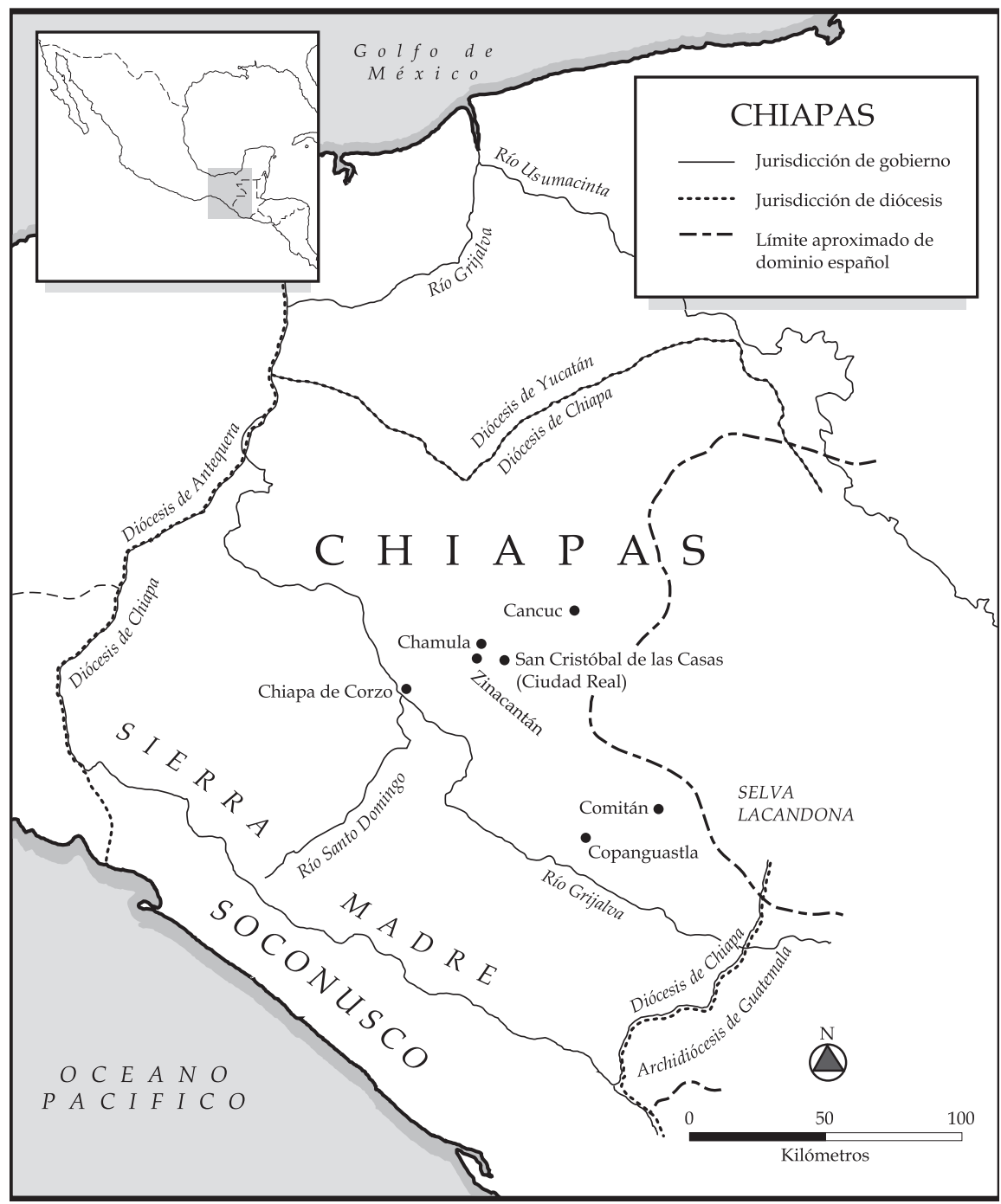


W. GEORGE LOVELL

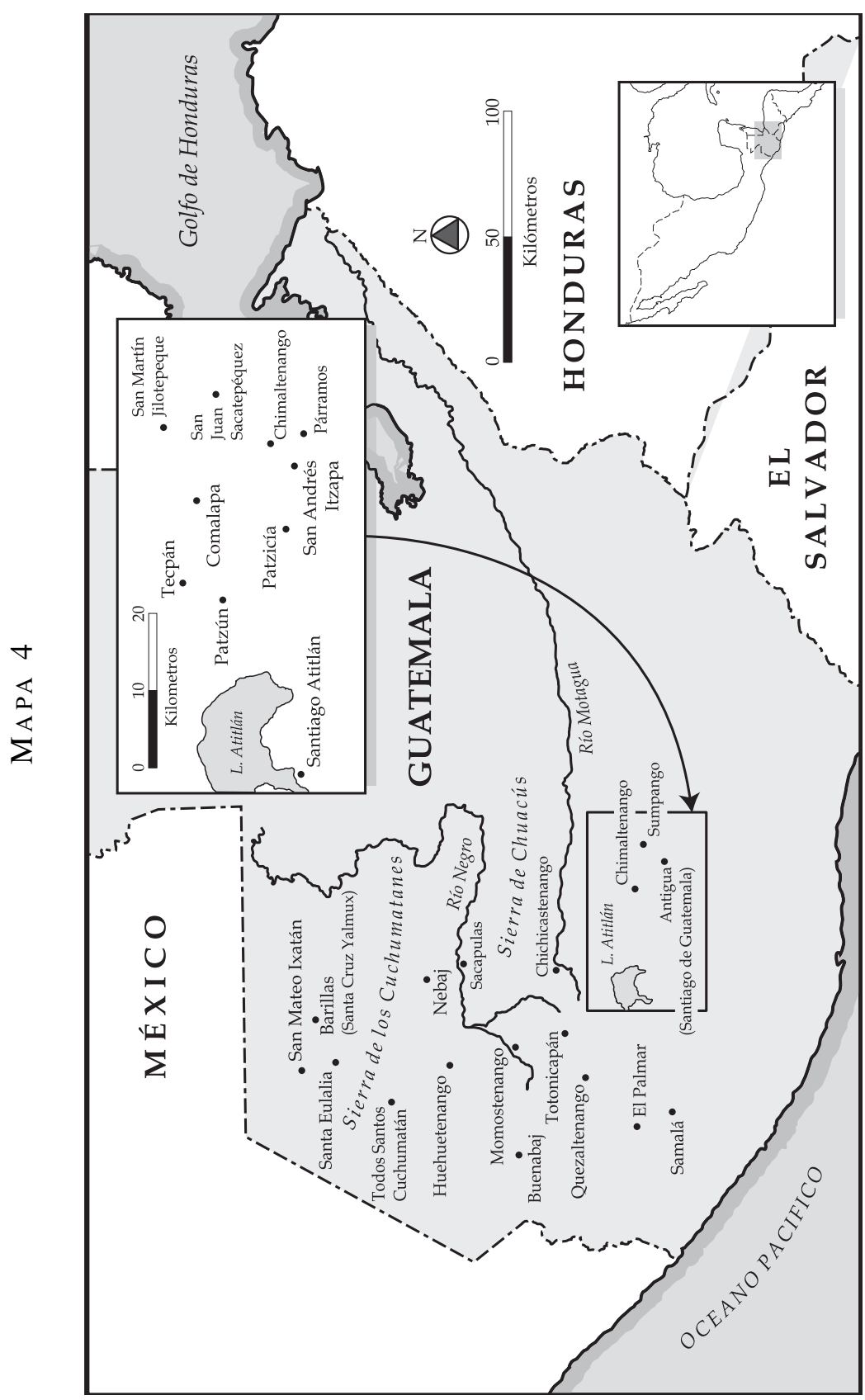

